\title{
Selective Optogenetic Activation of Rostral Ventrolateral Medullary Catecholaminergic Neurons Produces Cardiorespiratory Stimulation in Conscious Mice
}

\author{
Stephen B. G. Abbott, ${ }^{\star}$ Seth D. DePuy, ${ }^{\star}$ Thanh Nguyen, Melissa B. Coates, Ruth L. Stornetta, and Patrice G. Guyenet \\ Department of Pharmacology, University of Virginia, Charlottesville, VA 22908
}

Activation of rostral ventrolateral medullary catecholaminergic (RVLM-CA) neurons e.g., by hypoxia is thought to increase sympathetic outflow thereby raising blood pressure (BP). Here we test whether these neurons also regulate breathing and cardiovascular variables other than BP. Selective expression of ChR2-mCherry by RVLM-CA neurons was achieved by injecting Cre-dependent vector AAV2$\mathrm{EF} 1 \alpha$-DIO-ChR2-mCherry unilaterally into the brainstem of dopamine- $\beta$-hydroxylase ${ }^{\mathrm{Cr} / 0}$ mice. Photostimulation of RVLM-CA neurons increased breathing in anesthetized and conscious mice. In conscious mice, photostimulation primarily increased breathing frequency and this effect was fully occluded by hypoxia $\left(10 \% \mathrm{O}_{2}\right)$. In contrast, the effects of photostimulation were largely unaffected by hypercapnia $\left(3\right.$ and $6 \% \mathrm{CO}_{2}$ ). The associated cardiovascular effects were complex (slight bradycardia and hypotension) and, using selective autonomic blockers, could be explained by coactivation of the sympathetic and cardiovagal outflows. ChR2-positive RVLM-CA neurons expressed VGLUT2 and their projections were mapped. Their complex cardiorespiratory effects are presumably mediated by their extensive projections to supraspinal sites such as the ventrolateral medulla, the dorsal vagal complex, the dorsolateral pons, and selected hypothalamic nuclei (dorsomedial, lateral, and paraventricular nuclei).

In sum, selective optogenetic activation of RVLM-CA neurons in conscious mice revealed two important novel functions of these neurons, namely breathing stimulation and cardiovagal outflow control, effects that are attenuated or absent under anesthesia and are presumably mediated by the numerous supraspinal projections of these neurons. The results also suggest that RVLM-CA neurons may underlie some of the acute respiratory response elicited by carotid body stimulation but contribute little to the central respiratory chemoreflex.

\section{Introduction}

The catecholaminergic neurons that reside in the rostral half of the ventrolateral medulla (RVLM-CA neurons), also called C1 neurons, regulate arterial blood pressure (BP), the CRF/ACTH/ corticosterone cascade, and autonomic glucoprivic responses (Card et al., 2006; Guyenet, 2006; Schiltz and Sawchenko, 2007; Hodges et al., 2008; Li et al., 2009). The stimuli that most commonly activate the $\mathrm{C} 1$ neurons (nociception, hypotension, and hypoxia) also increase breathing (Sun and Spyer, 1991a,b; Hirooka et al., 1997; Schreihofer and Guyenet, 1997). Although pharmacological evidence suggests that catecholaminergic neurons regulate breathing (Zanella et al., 2006), a specific contribution of the RVLM-CA neurons to respiratory control has not

\footnotetext{
Received March 2, 2012; revised Dec. 18, 2012; accepted Jan. 2, 2013.

Author contributions: S.B.G.A., S.D.D., R.L.S., and P.G.G. designed research; S.B.A., S.D.D., T.N., M.C., R.L.S., and P.G.G. performed research; S.B.G.A., S.D.D., T.N., R.L.S., and P.G.G. analyzed data; S.B.A., S.D.D., R.L.S., and P.G.G. wrote the paper.

This work was supported by grants from the National Institutes of Health (HL28785 and HL74011 to P.G.G., 1F32HL096280-01 to S.D.D.) and a postdoctoral fellowship to S.B.G.A. from the American Heart Association (11post7170001)

*S.B.G.A. and S.D.D. contributed equally to this work.

Correspondence should be addressed to Dr. Patrice G. Guyenet, University of Virginia Health System, P.O. Box 800735, 1300 Jefferson Park Avenue, Charlottesville, VA 22908-0735. E-mail: pgg@virginia.edu.

DOI:10.1523/JNEUROSCI.1046-12.2013

Copyright $\odot 2013$ the authors $\quad 0270-6474 / 13 / 333164-14 \$ 15.00 / 0$
}

been demonstrated, particularly in vivo. Yet this hypothesis is plausible given their anatomical characteristics. For instance, RVLM-CA neurons are embedded within the respiratory network of the medulla oblongata and, in rats at least, these cells target several regions implicated in respiratory control such as the dorsomedial hypothalamic nucleus, the orexinergic neuron-rich region of the lateral hypothalamus, the lateral parabrachial nuclei, and the retrotrapezoid nucleus (RTN) (Chamberlin and Saper, 1992; DiMicco et al., 2002; Card et al., 2006; Guyenet et al., 2010; Li and Nattie, 2010). The goal of the present study is to investigate the cardiorespiratory response pattern to selective activation of the RVLM-CA neurons in conscious mice.

Lentiviral vectors engineered with the artificial promoter PRSx8 have been used to express channelrhodopsin2 (ChR2) or the allatostatin receptor in RVLM-CA neurons (Abbott et al., 2009a,b; Marina et al., 2010, 2011). With such vectors, transgene expression relies on the presence of transcription factors Phox $2(\mathrm{a} / \mathrm{b})$, which are expressed by several other types of VLM neurons in addition to the catecholaminergic neurons, e.g., the RTN and subsets of cholinergic neurons. The RTN is a major source of excitatory input to the respiratory network (Abbott et al., 2009a) and the cholinergic neuron population targeted with PRSx8-based vectors likely includes parasympathetic preganglionic neurons (Kang et al., 2007). Accordingly, such vectors are 
not sufficiently selective to identify unambiguously the contribution of RVLM-CA neurons to respiration or to the circulation.

To overcome this selectivity problem we used the optogenetic approach described by Cardin et al. (2010). We injected a Credependent adeno-associated viral vector serotype 2 (AAV2-DIOEF1 $\alpha$ - ChR2-mCherry) into the RVLM of mice that express Cre under the control of the dopamine- $\beta$ hydroxylase $(\mathrm{D} \beta \mathrm{H})$ promoter. This vector has two major theoretical advantages. It is extremely selective for the cells that express the Cre recombinase and it produces the robust level of ChR2 expression required for neuronal photostimulation (Cardin et al., 2010; Depuy et al., 2011). Using neuroanatomical methods, we verified that ChR2 was selectively expressed by the RVLM-CA neurons. We then used these mice to test whether selective activation of RVLM-CA neurons increases breathing and to examine the concomitant cardiovascular responses. Finally, we evaluated the effects of moderate hypoxia and hypercapnia on the respiratory effects of RVLM-CA neuron activation.

\section{Materials and Methods}

Animal use was in accordance with guidelines approved by the University of Virginia Animal Care and Use Committee. All experiments were conducted using D $\beta \mathrm{H}$-Cre mice (strain STOCK Tg(D $\beta \mathrm{H}$-cre)KH212Gsat/ Mmcd) developed by Dr. N. Heintz, Rockefeller University, New York, through the GENSAT project (Gong et al., 2003), founders procured from the Mutant Mouse Regional Resource Centers. The transgenic line was maintained as Cre hemizygous $\left(\mathrm{D} \beta \mathrm{H}^{\mathrm{Cre} / 0}\right)$ on a $\mathrm{C} 57 \mathrm{BL} / 6 \mathrm{~J}$ background acquired from The Jackson Laboratory and bred in house for experiments. A total of 40 mice ( 17 females and 23 males) were used for the experiments.

$A A V 2$ vectors. AAV2-DIO-EF1 $\alpha$-ChR2-mCherry was prepared using a construct (adeno-associated viral vector serotype 2 double-floxed inverted open reading frame ChR2-mCherry; (Cardin et al., 2009), which was kindly provided by K. Deisseroth, Stanford University, Stanford, CA. This vector features an enhanced version of the photosensitive cationic channel channelrhodopsin-2 (ChR2 H134R) fused to the reporter mCherry and under the control of the elongation factor $1 \alpha(\mathrm{EF} 1 \alpha)$ promoter. The ChR2-mCherry sequence is flanked by double lox (loxP and lox 2722) sites. The construct was amplified and sent to the University of North Carolina vector core for virus production of the AAV construct with serotype 2 (AAV2; titer: $10^{12}$ virus molecules per milliliter). The control vector (AAV2-DIO-EF1 $\alpha$-mCherry) was identical to the experimental vector except for the absence of ChR2, had the same titer, and was obtained from the University of North Carolina vector core.

Injection of AAV2 into the RVLM of $D \beta H^{C r e / 0}$ mice

$\mathrm{D} \beta \mathrm{H}^{\mathrm{Cre} / 0}$ mice of either sex (17 females and 23 males, age: $8-12$ weeks) were anesthetized with a mixture of ketamine $(100 \mathrm{mg} / \mathrm{kg})$ and dexmedetomidine $(0.2 \mathrm{mg} / \mathrm{kg})$ given intraperitoneally. Depth of anesthesia was assessed by an absence of the corneal and hindpaw withdrawal reflex. Additional anesthetic was administered as necessary (20\% of the original dose, i.p.). The following procedures were performed under aseptic conditions. Following skin shaving and disinfection, the skin overlying the left mandible was cut to reveal a short segment of the mandibular branch of the facial nerve. The mice were then placed prone on a Kopf 1730 stereotaxic apparatus adapted for mouse stereotaxic injections (ear bar adaptor, model EB-5N; Narashige Scientific Instrument Lab; bite bar, Model 926 mouse adaptor set at $-2 \mathrm{~mm}$; David Kopf Instruments). Body temperature was kept close to $37^{\circ} \mathrm{C}$ with a servo-controlled heating pad. A $1.5 \mathrm{~mm}$ diameter hole was drilled into the occipital plate on the left side caudal to the parieto-occipital suture. The viral vector was loaded into a $1.2 \mathrm{~mm}$ internal diameter glass pipette broken to a $25 \mu \mathrm{m}$ tip (external diameter). The facial nerve was stimulated $(0.1 \mathrm{~ms}, 1-300 \mu \mathrm{A}, 1 \mathrm{~Hz})$ to evoke antidromic field potentials within the facial motor nucleus according to a method previously used in rats (Brown and Guyenet, 1985). These field potentials were used to map the caudal end of the facial motor nucleus (FN) and help identify the location of the $\mathrm{C} 1$ neurons that reside caudal and slightly medial to this nucleus (see Fig. $1 A, B$ ). Strong respiration synchronous mass activity located exclusively caudal to the facial motor nucleus further helped in navigating to this region (Fig. $1 C$ ). Three $140 \mathrm{nl}$ injections of virus were made $300 \mu \mathrm{m}$ above the base of the medulla oblongata (determined as the lower limit of the facial field potential) and at the medial edge of the respiratory column. The injections were separated by $200 \mu \mathrm{m}$ and were aligned rostrocaudally (Fig. $1 A)$. Experimental mice $(N=34)$ were injected with AAV2-DIO-EF1 $\alpha$-ChR2-mCherry and control mice $(N=6)$ received AAV2-DIO-EF1 $\alpha$-mCherry.

For stimulation experiments in conscious mice, a guide cannula ( 9 experimental and 6 control mice) or a fiber optic (14 experimental mice) was implanted immediately following virus injections. The guide cannula ( $3 \mathrm{~mm}, 24 \mathrm{GA}$; Plastics One) extended $\sim 2 \mathrm{~mm}$ below the surface of the skull and was secured with cyanoacrylate adhesive (Loctite). The implantable fiber optic was constructed and implanted at a depth of 4.7 $\mathrm{mm}$ from the surface of the brain using published methods (Sparta et al., 2012), except that cyanoacrylate adhesive was used to secure the fiber to the skull. Four additional mice that received injections of AAV2-DIOEF1 $\alpha$-ChR2-mCherry vector, but were not implanted with a fiber optic, were used to test the interaction between hypoxia and hypercapnia.

In all mice, incisions were closed in two layers (muscle and skin) with silk sutures and surgical cyanoacrylate adhesive. Mice received postoperative boluses of atipamezole ( $\alpha 2$-adrenergic antagonist, Antisedan, 2 $\mathrm{mg} / \mathrm{kg}$, s.c.), ampicillin ( $125 \mathrm{mg} / \mathrm{kg}$, i.p.), and ketoprofen $(4 \mathrm{mg} / \mathrm{kg}$, s.c.) and were then placed in a heated environment $\left(37^{\circ} \mathrm{C}\right)$ until consciousness was regained before being returned to a clean home cage. Ampicillin and ketoprofen were administered 24 and $48 \mathrm{~h}$ postoperatively. Mice were housed in the UVa vivarium for $>4$ weeks before experimentation to allow sufficient expression of the ChR2-mCherry or mCherry transgene. During this time mice gained weight normally and appeared unperturbed by either the guide cannula or the implanted fiber.

Photostimulation of the ventrolateral medulla was performed using a diode-pumped solid state blue laser ( $473 \mathrm{~nm}$, CrystaLaser) controlled by TTL-pulses from a Grass model S88 stimulator (AstroMed). The light output at the tip of the fiber optic was measured with a light meter (Thorlabs) and adjusted for a final output of $8-9 \mathrm{~mW}$.

\section{Physiological experiments in anesthetized mice}

Mice $(N=7)$ were anesthetized with a mixture of ketamine $(100 \mathrm{mg} / \mathrm{kg})$ and dexmedetomidine $(0.2 \mathrm{mg} / \mathrm{kg})$ given intraperitoneally. The entire experiment, including surgery and recordings, lasted $<2 \mathrm{~h}$. One anesthetic booster ( $20 \%$ of the original dose, i.p.) was typically required to maintain satisfactory anesthesia throughout the experiment, monitored by lack of hindlimb retraction to toe pinch. At the completion of the experiment, mice were given additional anesthetic and were perfused according to the methods detailed below.

The mice were placed prone on a stereotaxic apparatus designed for rats using the mouse adaptors described above. The adaptor was outfitted with a nose mask (Kopf model 907) through which $100 \%$ oxygen was delivered. Body temperature was kept close to $37^{\circ} \mathrm{C}$ with a servocontrolled heating pad and a blanket. Diaphragmatic electromyography (EMG) was recorded as previously described (Depuy et al., 2011). Signal processing occasionally included additional digital bandpass narrowing to minimize the electrocardiography artifact. This was followed by signal rectification and integration (0.03 s time constant). EMG respiratory frequency $\left(\mathrm{EMG} \mathrm{f}_{\mathrm{R}}\right)$ was triggered from the integrated EMG signal. EMG amplitude was measured using a peak detection feature of the Spike 2 software. The product of EMG $\mathrm{f}_{\mathrm{R}}$ and EMG amplitude was taken as an index of overall inspiratory neural output and was expressed in arbitrary units.

A $1.5 \mathrm{~mm}$ diameter hole was drilled into the occipital plate on the left side to insert the optical fiber vertically $(0.2 \mathrm{~mm}$ core, 0.37 numerical aperture; Thorlabs). To photostimulate the $\mathrm{C} 1$ cells the tip of the fiber optic was inserted $200-300 \mu \mathrm{m}$ dorsal to where the viral vector had previously been injected (typically $1.1 \mathrm{~mm}$ lateral to the midline, $1.3-1.5$ $\mathrm{mm}$ caudal to the parieto-occipital suture, $4.8-5.4 \mathrm{~mm}$ below the dorsal surface of the brain). Control photostimulation was performed $2.5 \mathrm{~mm}$ dorsal to the ventrolateral medulla sites, i.e., within the cerebellum. Ep- 
isodes of hypercapnia were produced by adding $\mathrm{CO}_{2}$ into the oxygen line supplying the mouse (inspired $\mathrm{CO}_{2}$ concentration was measured with a calibrated capnometer).

Light-evoked changes in breathing were determined as follows. EMG $\mathrm{f}_{\mathrm{R}}$, EMG amplitude, and the product of these parameters were measured during the minute preceding the photostimulation episode and were remeasured during the second minute after the end of the photostimulus, i.e., after full recovery. The average of these two values was considered as the baseline. The parameters were measured during the last $15 \mathrm{~s}$ of the photostimulation episodes and the effect of the light was calculated as a percentage increase from baseline. The effects of $\mathrm{CO}_{2}$ were examined in a similar fashion by comparing the values of the respiratory variables during the last minute of a 5 min hypercapnic exposure $\left(8 \% \mathrm{CO}_{2}\right)$ to the averaged pretest and post test baseline. Results were compared using a Kruskal-Wallis one-way ANOVA on ranks followed by all multiple comparisons (Dunn's method; significance set at $p<0.05$ ).

\section{Physiological experiments in conscious mice}

Breathing parameters were evaluated in conscious unrestrained mice using whole-body plethysmography (EMKA Technologies). The chamber was continuously flushed with dry room temperature air delivered by three computer-driven mass flow regulators (Alicat Scientific) controlling flow of $\mathrm{O}_{2}, \mathrm{~N}_{2}$, and $\mathrm{CO}_{2}(0.5-1 \mathrm{~L} / \mathrm{min})$. An estimation of tidal flow was calculated using the equation of Drorbaugh and Fenn (1955) derived from a differential pressure sensor connected to the plethysmography chamber and calibrated to air injected from a $1 \mathrm{ml}$ syringe. The flow signal was amplified $(\times 500)$ and acquired at $1 \mathrm{kHz}$ using EMKA IOX 2.8 (EMKA Technologies) and Spike 2 software (v7.06, CED). Chamber temperature, relative humidity, and atmospheric pressure were continuously monitored and were very stable within experiments (temperature; $24.8 \pm 0.1^{\circ} \mathrm{C}$, relative humidity; $42.4 \pm 1.8 \%, N=15$ ). Body temperature was not measured.

Mice implanted with a guide cannula were placed in the plethysmography chamber on the day of the experiment and habituated to chamber conditions for $2-3 \mathrm{~h}$. At this point, mice were briefly ( $<10 \mathrm{~min})$ anesthetized with isoflurane ( $1.2 \%$ maintenance after $2.5 \%$ induction in $\mathrm{O}_{2}$ ) to allow for insertion of a custom optical fiber assembly into the implanted guide. A fiber depth of 2-3 mm below the base of the guide cannula pedestal produced the best results. Mice were returned to the plethysmography chamber and allowed to recover from anesthesia for over $1 \mathrm{~h}$ before commencing experimental protocols. At the completion of the experiment, these mice were anesthetized and perfused according to the methods detailed below. These mice were used to determine the effects of photostimulation on breathing in experimental versus control mice.

Mice instrumented with an implantable optical fiber were evaluated on multiple nonconsecutive days in the plethysmography chamber, after which they were anesthetized and perfused according to the methods detailed below. In these mice, a $200 \mu \mathrm{m}$ thick multimode optical fiber terminated with a $1.25 \mathrm{~mm}$ zirconia ferrule was mated to the implanted ferrule with a zirconia sleeve (Sparta et al., 2012) under light anesthesia ( $2 \%$ isoflurane $<1 \mathrm{~min}$ ). Optical matching gel (Fiber Instrument Sales) was applied at the ferrule junction to reduce light loss. These mice were used to evaluate the effects of photostimulation on breathing during normoxia $\left(21 \% \mathrm{O}_{2}\right.$, balanced by $\left.\mathrm{N}_{2}\right)$, hyperoxia $\left(100 \% \mathrm{O}_{2}\right)$, and $5 \mathrm{~min}$ challenges of hyperoxic hypercapnia ( 3 and $6 \% \mathrm{CO}_{2}$, balanced by $\mathrm{O}_{2}$ ) or poikilocapnic hypoxia ( 10 and $15 \% \mathrm{O}_{2}$, balanced by $\mathrm{N}_{2}$ ). For hyperoxic hypercapnia and poikilocapnic hypoxia, stimulation was conducted during the fourth minute of the challenge. Brief challenges of $\mathrm{CO}_{2}(15 \mathrm{~s}$ of $15 \% \mathrm{CO}_{2}$ at $0.5 \mathrm{~L} / \mathrm{min}$ ) were conducted under normoxic and hypoxic conditions in six mice. The $\mathrm{CO}_{2}$ challenge was executed 4 min after the onset of hypoxia, and peak ventilatory effects were extracted from a stable period of breathing $30-45 \mathrm{~s}$ from the onset of hypercapnia.

A subset of mice instrumented with implantable optical fibers were implanted with radio-telemetry probes $(N=6$, PA-C10; Data Sciences International) 3 weeks after virus injection to measure arterial pressure from the left carotid artery, as previously described (Butz and Davisson, 2001). Following recovery ( $>1$ week), these mice were placed in the plethysmography chamber as described above for simultaneous recording of respiratory parameters and pulsatile BP $(1 \mathrm{kHz}$ sampling fre- quency, Spike 2 software). In addition to breathing parameters $\left(f_{R}, V_{T}\right.$, $\mathrm{MV}$ ) extracted as described earlier, mean blood pressure (MBP $=$ diastolic pressure $+1 / 3$ (systolic pressure - diastolic pressure) ) and heart rate $(\mathrm{HR})$ were calculated from pulsatile $\mathrm{BP}$ recordings based on values calibrated before implantation of the telemetry probe. These mice were used to determine the cardiovascular and respiratory effects of photostimulation before and after administration of sterile saline, methylatropine $(1 \mathrm{mg} / \mathrm{kg}$ in sterile saline at $0.1 \mathrm{mg} / \mathrm{ml}$; Sigma-Aldrich), propranolol (10 mg/kg in sterile water at $0.2 \mathrm{mg} / \mathrm{ml}$; Tocris Bioscience), and prazosin $(1 \mathrm{mg} / \mathrm{kg}$ sonicated in sterile water at $0.1 \mathrm{mg} / \mathrm{ml}$, SigmaAldrich). In these experiments, mice were briefly removed from the chamber to administer drugs or vehicle via intraperitoneal injection, then replaced in the chamber and allowed at least $15 \mathrm{~min}$ for the effects of handling to subside and the drugs to take effect and before commencing photostimulation trials.

In mice tested in the conscious state, the respiratory and cardiovascular effects of $30 \mathrm{~s}$ photostimulation trains of light pulses (frequency: 5, 10, or $20 \mathrm{~Hz}$; pulse duration: 1, 2, or $5 \mathrm{~ms}$ ) were determined by extracting average resting values from the $10 \mathrm{~s}$ preceding the stimulus onset and average values from the first $5-10 \mathrm{~s}$ and last $5-10 \mathrm{~s}$ of a stimulus. Multiple trials for each condition were averaged for each mouse and the result was subsequently averaged between mice. Values were taken during periods of inactivity (quiet waking) or sleep, as behavioral breathing (e.g., sniffing) and body movement distorted the flow trace. In many trials, small postural changes occurred during the last $10 \mathrm{~s}$ of the stimulation or during the poststimulation hypoventilatory period. These periods were excluded from the analysis, except where time course effects are presented. Results are presented as mean \pm SEM except when noted. Statistical analysis was performed using GraphPad Prism software (v5) and included an assessment of normality, Student's $t$ test (paired-effect of saline vs prazosin on cardiorespiratory effects of stimulation, unpairedeffect of hyperoxia vs normoxia on basal ventilation and $f_{R}$ effects of stimulation), repeated measures one-way ANOVA with Bonferroni's post test $\left(\mathrm{f}_{\mathrm{R}}\right.$ time course in Fig. $\left.4 \mathrm{D}\right)$, two-way ANOVA with either Bonferroni's or Dunnett's post tests (repeated measures-effect of stimulation frequency and pulse width on increase in $f_{R}$ in experimental mice, respiratory effects of photostimulation during hypercapnia or hypoxia, cardiovascular effects of photostimulation after pharmacology interventions, unmatched-normalized $\mathrm{f}_{\mathrm{R}}$ effect of stimulation vs $\mathrm{CO}_{2}$ during hypoxia), and linear regression with analysis of covariance (relationship between resting $f_{R}$ and increase in $f_{R}$ during stimulation).

\section{Histological experiments}

Perfusions and brain sectioning. Mice were anesthetized with an overdose of pentobarbital and perfused transcardially with $10 \mathrm{ml}$ of heparinized saline followed by $75 \mathrm{ml}$ of freshly prepared $4 \%$ paraformaldehyde in 100 mM sodium phosphate buffer, $\mathrm{pH}$ 7.4. Brains were extracted and postfixed at $4^{\circ} \mathrm{C}$ for $24-72 \mathrm{~h}$ in the same fixative. Coronal sections were cut at $30 \mu \mathrm{m}$ on a vibrating microtome and stored in a cryoprotectant solution (20\% glycerol plus 30\% ethylene glycol in $50 \mathrm{~mm}$ phosphate buffer, $\mathrm{pH}$ 7.4) at $-20^{\circ} \mathrm{C}$ waiting further processing.

Immunohistochemistry. All sections were processed free floating. All procedures were conducted at room temperature unless otherwise noted. For fluorescence immunohistochemistry sections were rinsed, and incubated in a blocking solution of $10 \%$ horse serum, then rinsed and incubated with primary antibody at $4^{\circ} \mathrm{C}$ overnight. Sections were then rinsed and incubated with secondary antibody for 45-60 min. Sections were rinsed and mounted onto glass slides, air dried, and dehydrated through a series of graded alcohols and xylenes and covered with DPX mounting media.

3-3'-diaminobenzidine immunohistochemistry. Sections were rinsed and incubated in $1 \%$ hydrogen peroxide, then blocked with TNB blocking solution (PerkinElmer) according to manufacturer's instructions. Sections were incubated with primary antibody at $4^{\circ} \mathrm{C}$ overnight. Some sections were reacted for 3-3'-diaminobenzidine (DAB) colorization after the overnight incubation in primary antibody. These sections were rinsed and incubated with donkey anti-rabbit biotinylated-IgG (Vector Laboratories) for 45-60 min. Sections were rinsed and incubated in ABC solution (Vector Laboratories) for $30 \mathrm{~min}$ according to manufacturer's 
A
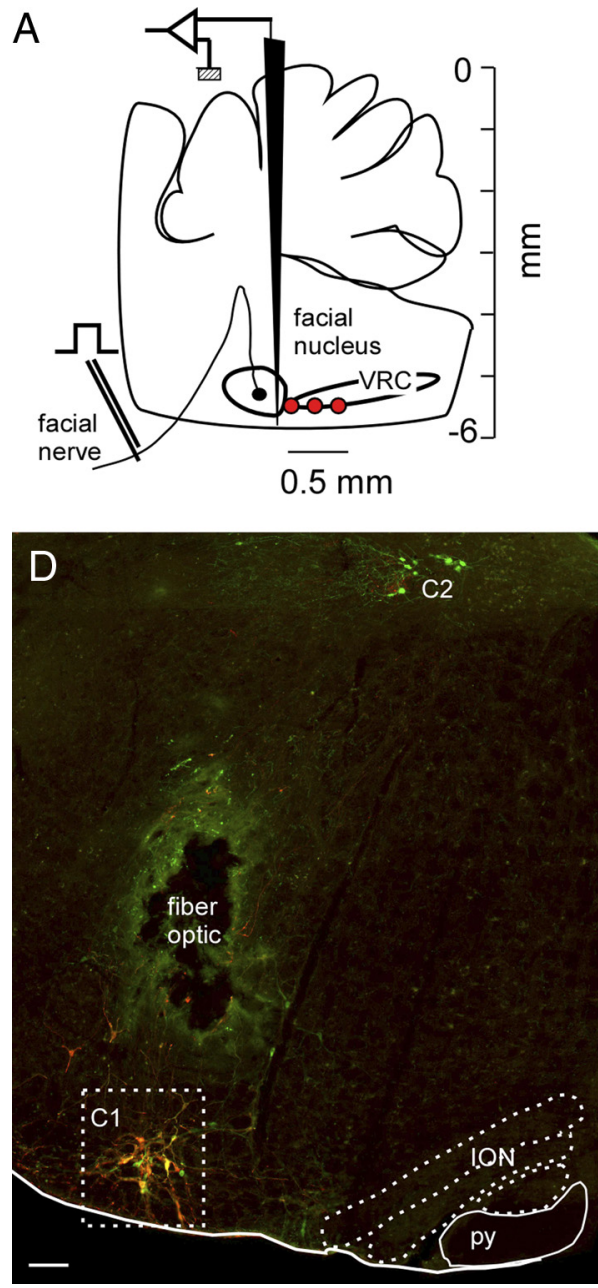

B

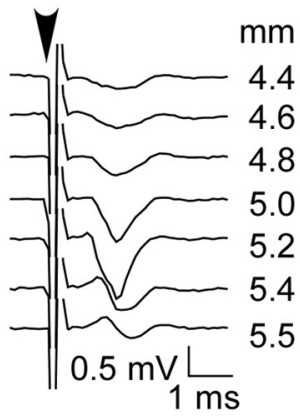

C

VRC

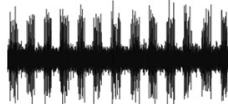

$\frac{0.2 \mathrm{mV}}{1 \mathrm{~s}}$

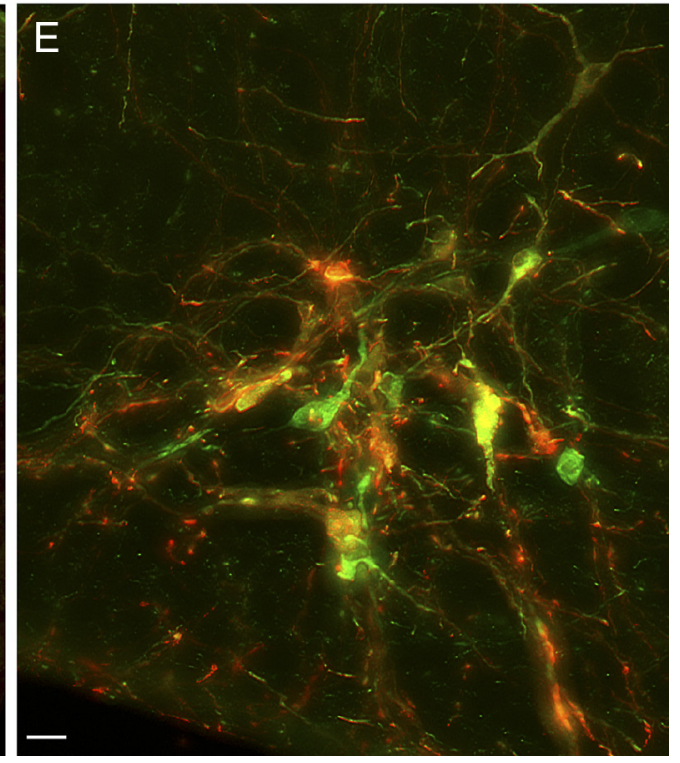

Figure 1. Selective expression of ChR2-mCherry in RVLM-CA neurons in D $\beta H^{C r e / 0}$ mice. $A$, The AAV2 vector was microinjected at the medial edge of the ventral respiratory column (VRC; red dots). These sites were identified electrophysiologically by their anatomical proximity to the facial motor nucleus. $\boldsymbol{B}$, Example of antidromic field potentials recorded in the facial motor nucleus as the AAV2-containing injection pipette was lowered through the medulla oblongata. C, Multiunit respiratory activity recorded just caudal to the facial motor nucleus, further defining the AAV2 injection sites. D, Transverse hemisection through the left medulla oblongata of a $\mathrm{D} \beta \mathrm{H}^{\text {Cre/0 }}$ mouse that received injections of AAV2-DI0-ef1 $\alpha$-ChR2-mCherry 4 weeks prior into the left RVLM. $\mathrm{mCherry} \mathrm{(red)}$ and TH (green) are both detected by immunofluorescence. In the C1 region of the RVLM, a majority of the CA neurons expressed the mCherry transgene (yellow/orange). The dorsal group of CA neurons (C2) was not transduced. The lesion was caused by the insertion of the fiber optic, the green color surrounding the lesion is a histological artifact. ION, inferior olivary nucleus; py, pyramidal tract. $\boldsymbol{E}$, enlargement of the $\mathbf{C} 1$ region outlined in $\boldsymbol{D}$. Scale bars: in $\boldsymbol{D}, 100 \mu \mathrm{m} ; \boldsymbol{E}, 20 \mu \mathrm{m}$.

instructions. Sections were then rinsed and incubated for $4-8 \mathrm{~min}$ in $\mathrm{DAB}$ using the DAB peroxidase substrate kit according to manufacturer's instructions (Vector Laboratories). Sections were finally rinsed, mounted, and dehydrated as described above.

Antibodies. mCherry protein was detected using a cross-reacting antiDsRed antibody (rabbit polyclonal, 1:500; Clontech \#632496, Clontech Laboratories). For fluorescence histochemistry, the secondary antibody Cy3-tagged anti-rabbit-IgG (1:200; Jackson ImmunoResearch) was used to visualize mCherry-immunoreactivity as red fluorescence. Tyrosine hydroxylase (TH) was detected with a sheep polyclonal antibody (Millipore \#AB1542; EMD Millipore) used at 1:2000 dilution. Alexa Fluor 488-tagged donkey anti-sheep antibody (1:200; Jackson ImmunoResearch) was used as secondary antibody to visualize TH immunoreactivity as green fluorescence. VGLUT2 was detected with anti-VGLUT2 antibody (guinea pig polyclonal, 1:2000; Millipore \#AB2251, Millipore) with Alexa Fluor 488-tagged donkey anti-guinea pig (1:200; Jackson ImmunoResearch) as the secondary antibody to visualize VGLUT2- immunoreactivity as green fluorescence.

\section{Microscopy}

All brain sections were examined under bright field and epifluorescence using a Zeiss AxioImager Z.1 microscope with computer controlled stage using the Neurolucida software (v10; MBF Bioscience). Terminal fields were mapped using a $63 \times$ oil-immersion objective by taking $0.3 \mu \mathrm{m}$ $z$-stack images of both red and green fluorescence through the tissue where discernible mCherry-labeled fibers were sharply in focus. These stacks were usually between 5 and $10 \mu \mathrm{m}$ in depth. Terminals were marked as positive only where both mCherry and TH immunofluorescent profiles were in focus in at least two consecutive $z$ sections. Images were obtained with a Zeiss MRC camera as TIFF files $(1388 \times 1040$ pixels) and imported into Canvas software (v10; ACD Systems) for composing final figures. Output levels were adjusted to include all information-containing pixels. Balance and contrast was adjusted to reflect true rendering as much as possible. No other "photo-retouching" was done.

\section{Results}

Selective transduction of RVLM-CA neurons in the $\mathrm{D} \beta \mathrm{H}^{\mathrm{Cre} / 0}$ mouse

All cells expressing the transgene after injection of the AAV2EF1 $\alpha$-DIO-ChR2-mCherry vector were located in the RVLM. These cells were virtually all $\mathrm{TH}$-immunoreactive ( $\mathrm{TH}$-ir) hence catecholaminergic (Fig. 1D,E). Lower brainstem CA neurons located outside the RVLM were not transduced (e.g., locus ce- 
A1
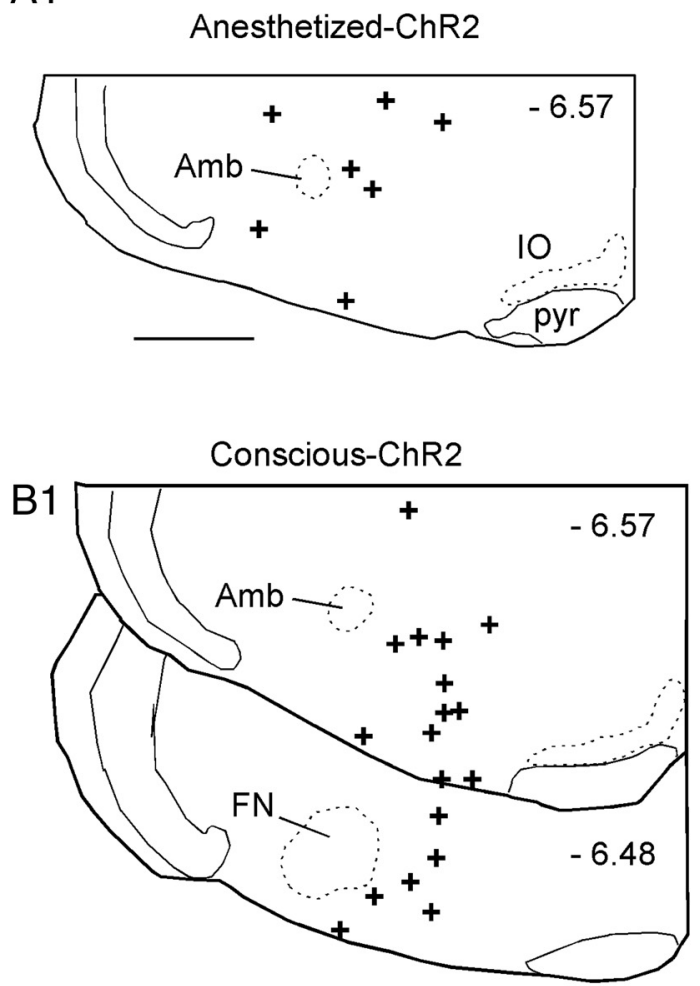

C1

\section{Conscious-Control vector}

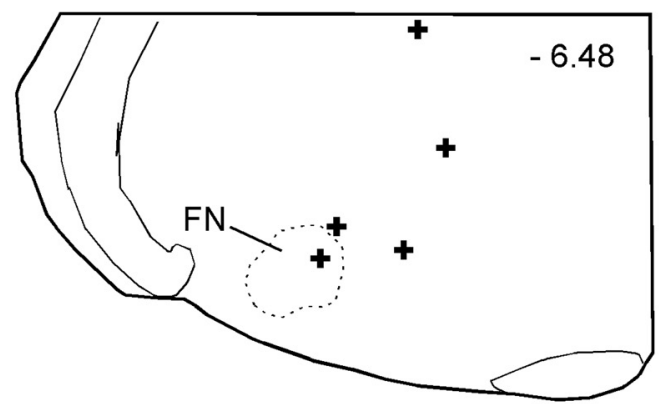

A2

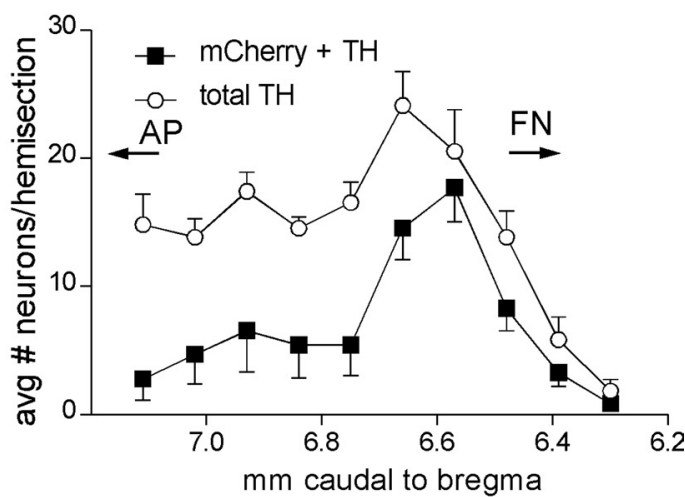

B2

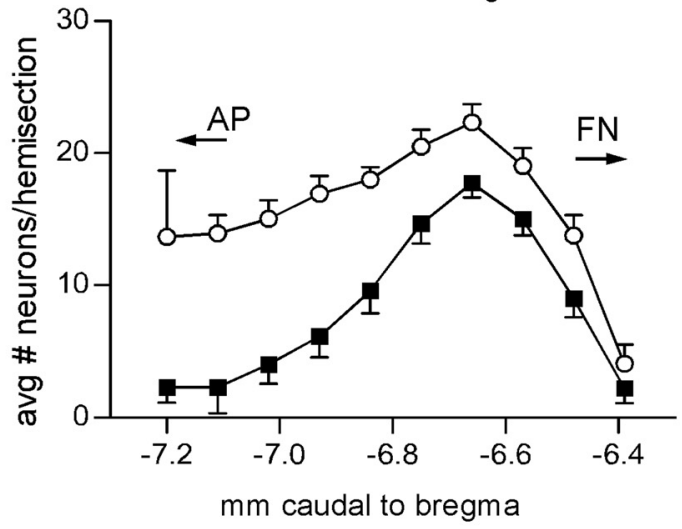

$\mathrm{C} 2$

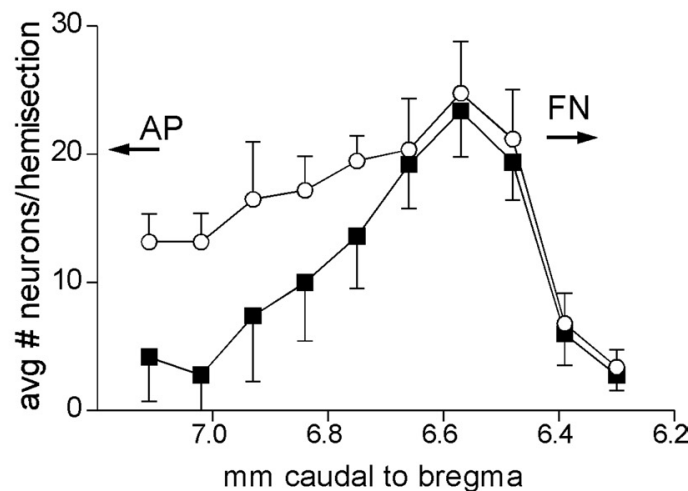

Figure 2. Anatomical distribution of the ChR2-expressing CA neurons and the location of the fiber optic tip. A1-C1, Fiber optic tip placements for the experiments identified above the drawings. Approximate distance from bregma shown in each section (top right). Scale bar: (in A1) A1-C1,0.5 mm. A2-C2, Grouped rostrocaudal distribution of the RVLM-CA neurons (filled square, neurons ir for both mCherry and TH; open circles, total TH-ir neurons). Cells counted on left (injection) side only. AP with the arrow indicates the rostral tip and caudal extent of the area postrema. FN with the arrow indicates the caudal most location and rostral extension of the facial motor nucleus. Amb, Compact formation of the nucleus ambiguus; I0, inferior olive; pyr, pyramidal tract.

ruleus, A5, and the A2 and C2 groups located in the dorsomedial medulla; the latter are illustrated in Fig. 1D).

The rostrocaudal distribution of the transgene-expressing neurons was analyzed in most mice. The first group of mice $(N=$ 7) received injections of AAV2-EF1 $\alpha$-DIO-ChR2-mCherry vector into the RVLM and were used for experiments under anesthesia (Fig. 2A). In this group, $69 \pm 14$ neurons (counted in 1 -in-3 sections) expressed mCherry, and $99.6 \pm 0.5 \%$ of these neurons also expressed TH. In mice injected with the same vector, which were used for plethysmography experiments in the conscious state (Fig. 2B), $76 \pm 7$ neurons (counted in 1-in-3 sections; $N=18$ ) expressed mCherry, and $98.9 \pm 0.2 \%$ of these neurons also expressed TH. In mice injected with the control vector (AAV2-EF1 $\alpha$-DIO- mCherry), $116 \pm 27$ neurons (counted in 1-in-3 sections; $N=5$ ) expressed mCherry, $96.6 \pm$ $1 \%$ of which also expressed TH. Note that in the three groups, the vast majority of the transduced catecholaminergic neurons were confined to the RVLM, i.e., the portion of the ventrolateral medulla that extends rostral to a coronal plane that intersects the area postrema (Fig. 2, AP). Approximately half of all TH-ir neurons located rostral to the area postrema expressed the transgene ( $48 \pm 9 \%, 54 \pm 1 \%$, or $72 \pm 4 \%$ in the anesthetized, conscious, and control vector cases, respectively) (Fig. 2A2-C2). This proportion was greater in the rostral region where the vector injections were targeted. The fiber optic placements were very similar in mice expressing ChR2-mCherry and mCherry alone (Fig. 2A1-C1).

Photostimulation of RVLM-CA neurons increases breathing in anesthetized $\mathrm{D} \beta \mathrm{H}^{\mathrm{Cre} / 0}$ mice

In anesthetized mice freely breathing pure oxygen, the basal diaphragmatic EMG (dEMG) frequency was $186 \pm 11$ bpm (range: 


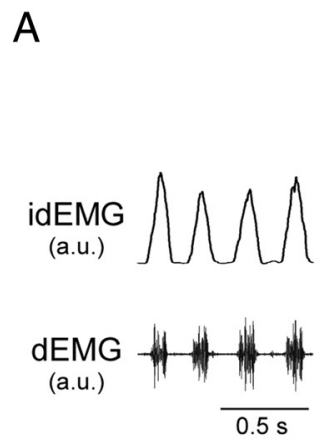

C1

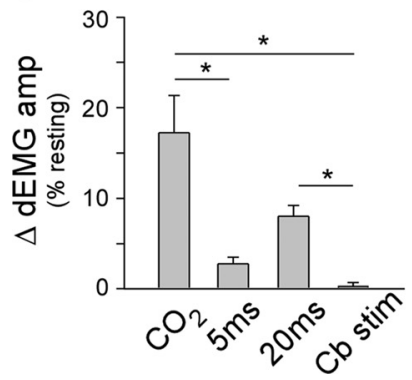

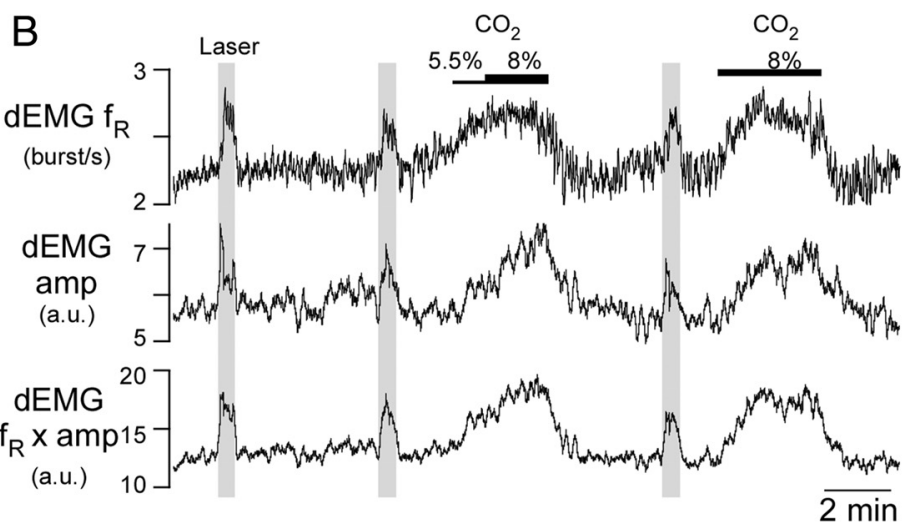

C2

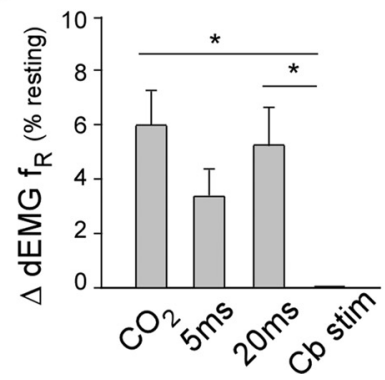

C3

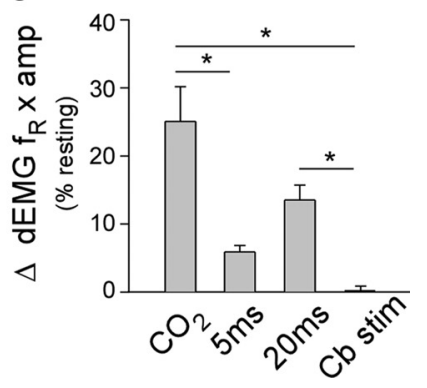

Figure 3. Selective activation of RVLM-CA neurons activates breathing in anesthetized D $\beta \mathrm{H}^{\text {Cre/0 }}$ mice. $A$, Representative recording of dEMG from an anesthetized mouse (bottom, raw signal; top, rectified and integrated signal, idEMG). $\boldsymbol{B}$, Breathing activation produced in a representative anesthetized mouse by hypercapnia and stimulation of (hR2-transfected RVLM-CA neurons with laser

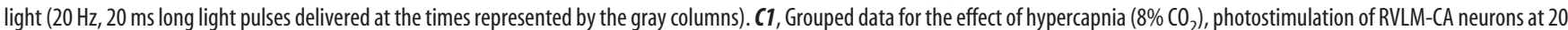
$\mathrm{Hz}$ with $5 \mathrm{~ms}$ or 20 ms light pulses, and photostimulation of the cerebellum (Cb stim) on dEMG amp $\left(N=7 ;{ }^{*} p<0.05\right)$. C2, As per $\mathbf{C 1}$ for EMG $\mathrm{f}_{\mathrm{R}}\left(\mathrm{N}=7\right.$; $\left.{ }^{*} p<0.05\right)$. $\mathbf{C 3}$, As per $\mathbf{C 1}$ for $\mathrm{f}_{\mathrm{R}} \times \mathrm{dEMG}$ $\operatorname{amp}\left(N=7 ;{ }^{*} p<0.05\right)$.

Table 1. Breathing effects elicited by photostimulating ChR2-expressing RVLM-CA neurons in conscious mice

\begin{tabular}{|c|c|c|c|c|c|c|c|}
\hline & $N$ & Baseline $V_{T}(\mu l / g)$ & Stimulated $V_{\mathrm{T}}(\mu \mathrm{l} / \mathrm{g})$ & Baseline $\mathrm{f}_{\mathrm{R}}(\mathrm{bpm})$ & Stimulated $\mathrm{f}_{\mathrm{R}}(\mathrm{bpm})$ & Baseline MV ( $\mu \mathrm{l} / \mathrm{g} / \mathrm{min})$ & Stimulated MV $(\mu \mathrm{l} / \mathrm{g} / \mathrm{min})$ \\
\hline ChR2 vector & 9 & $8.5 \pm 0.5$ & $8.0 \pm 0.4^{* * *}$ & $121.6 \pm 5.4$ & $164.5 \pm 6.4$ & $1014 \pm 41$ & $1309 \pm 87^{*}$ \\
\hline Control vector & 6 & $8.8 \pm 0.9$ & $8.7 \pm 0.9$ & $111.4 \pm 8.4$ & $114.5 \pm 9.3$ & $971 \pm 105$ & $978 \pm 111$ \\
\hline
\end{tabular}

Results analyzed by two-way ANOVA. Breathing frequency $\left(\mathrm{f}_{\mathrm{R}}\right): p=0.009$ for the interaction between ChR2 and stimulation; tidal volume $\left(\mathrm{V}_{\mathrm{T}}\right): p=0.74$ for the interaction between ChR2 and stimulation; minute volume $(\mathrm{MV}): p=0.11$ for the interaction between ChR2 and stimulation, $p=0.038$ for the effect of CHR2. ${ }^{*} p<0.05$, ${ }^{* * *} p<0.001$, Bonferroni post-test comparison between baseline and stimulation.

134-224). Photostimulation of the RVLM produced a modest but consistent increase in $\mathrm{f}_{\mathrm{R}}$ and the amplitude of the dEMG (Fig. $3 B, C)$. Total ventilation ( $f_{\mathrm{R}} \times$ dEMG amplitude) was also increased significantly (Fig. $3 B, C$ ). Respiratory stimulation produced by photostimulation was somewhat smaller than that elicited by hypercapnia ( $8 \% \mathrm{CO}_{2}$, balance oxygen) (Fig. $3 B$; group data in Fig. 3C1-C3). The breathing stimulation depended on the duration of the light pulses. The effects produced when using 20 $\mathrm{ms}$ pulses, but not $5 \mathrm{~ms}$ pulses, was significantly different from the effects of photostimulation of the cerebellum at a site $2.5 \mathrm{~mm}$ dorsal to the RVLM (control in Fig. 3C1-C3).

\section{Activation of ChR2-expressing RVLM-CA neurons increases breathing in conscious mice}

Photostimulation of ChR2-expressing RVLM-CA neurons in conscious mice in hyperoxic conditions (100\% oxygen) produced a marked increase in $\mathrm{f}_{\mathrm{R}}$ and small changes in $\mathrm{V}_{\mathrm{T}}$, resulting in a significant increase in MV (Table 1; Fig. 4A-D). The breathing stimulation increased as a function of the light pulse frequency (Fig. $4 B, D$ ), but did not vary according to the duration of the light pulses (1-5 ms) (Fig. $4 C$ ). The effects of photostimulation on $f_{R}$ were very reproducible within each animal and we did not observe a significant run-down of the effect over the course of an experiment. Photostimulation in control mice in which
RVLM-CA neurons expressed mCherry alone had no effect on breathing (Table 1; Fig. 4B,C). The breathing stimulation produced by the light in the experimental group was therefore entirely dependent on the expression of ChR2 by the RVLM-CA neurons.

In the experimental mice (i.e., expressing ChR2), respiratory stimulation was virtually instantaneous and was maximal at the start of the stimulus. After the initial increase, $\mathrm{f}_{\mathrm{R}}$ declined progressively during the course of the stimulus, reaching a steady state $\sim 15-20 \mathrm{~s}$ after the onset of the stimulus (Fig. $4 D$ ). A significant albeit short-lasting increase in $\mathrm{f}_{\mathrm{R}}$ was observed with stimulus frequencies as low as $5 \mathrm{~Hz}$ (Fig. 4D). The stimulation period was followed by a period of hypopnea (reduced ventilation) that varied in severity and duration according to the magnitude of the previous stimulus-evoked activation of $\mathrm{f}_{\mathrm{R}}$ and was absent if stimulation trials were conducted under hypercapnic conditions (change in $\mathrm{f}_{\mathrm{R}}$ during hypoventilatory period relative to prestimulus values during $0 \% \mathrm{CO}_{2}$ vs $6 \% \mathrm{CO}_{2}:-31.1 \pm 8.1$ vs $4.1 \pm 9.9$ breaths/min, $p=0.014, N=9$ ).

Respiratory motor output can be entrained to the phasic activation of muscle afferents (Potts et al., 2005) and other neurons (e.g., retrotrapezoid) (Abbott et al., 2011) that provide strong excitatory inputs to the central respiratory controller. We applied either single or twin light pulses intermittently to determine 
whether phasic stimulation of RVLM-CA neurons could evoke a similar entrainment of breathing. This paradigm only produced a weak entrainment of breathing rhythm at frequencies slightly greater than resting $f_{R}$ in the six animals tested (Fig. 4E); however, attempts to entrain breathing at higher frequencies failed.

We occasionally observed bouts of hyperventilation (i.e., high-frequency inspiratory efforts) during the last $10 \mathrm{~s}$ of the stimulus and superimposed over the poststimulus hypoventilatory period (Fig. $5 A)$. Hyperventilation was typically associated with postural changes and small body movements, and also occurred during hypercapnia in the absence of poststimulus hypoventilation (Fig. 5A).

\section{Activation of RVLM-CA neurons and the respiratory chemoreflex}

The next experiments were designed to test the interactions between the respiratory effects of stimulating RVLM-CA neurons and the central and peripheral chemoreflexes (Fig. 5). Hypercapnic challenges were conducted under hyperoxic conditions ( $94 \%$ oxygen) to reduce the contribution of the carotid bodies to the ventilatory effects of $\mathrm{CO}_{2}$ and therefore approximate pure central chemoreceptor stimulation. Graded elevation of inspired $\mathrm{CO}_{2}(3$ and $6 \%)$ caused graded increases in $\mathrm{f}_{\mathrm{R}}, \mathrm{V}_{\mathrm{T}}$, and $\mathrm{MV}(p<0.0001$ for the effect of $\mathrm{CO}_{2}$ on $\mathrm{f}_{\mathrm{R}}, \mathrm{V}_{\mathrm{T}}$, and $\mathrm{MV}, \mathrm{N}=9$ ) (Fig. $5 A$, traces $1-3$ from top, $B 1-B 3$ ). The effect of photostimulation on respiratory frequency was attenuated when $\mathrm{CO}_{2}$ was elevated ( $p=0.0004$ for the interaction between $\mathrm{CO}_{2}$ and photostimulation; two-way ANOVA) but nonetheless persisted even in the presence of $6 \% \mathrm{CO}_{2}$ despite the massive elevation of baseline $f_{R}$ (Fig. 5B1). However, MV was increased during stimulation regardless of the prevailing $\mathrm{CO}_{2}$ conditions $(p=0.77$ for the interaction between $\mathrm{CO}_{2}$ and photostimulation; two-way ANOVA). This result implies a weak interaction between the respiratory effects of activating RVLM-CA neurons and the central networks underlying the respiratory effects of $\mathrm{CO}_{2}$.

Basal ventilatory parameters were similar under hyperoxic and normoxic conditions, as was the increase in $\mathrm{f}_{\mathrm{R}}$ caused by RVLM-CA neuron stimulation (normoxia vs hyperoxia: $50.2 \pm 5.4$ vs $63.4 \pm 7.8$ breaths $/ \mathrm{min}, N=7$ and 9 , respectively, $p=0.21$ ) (Fig. 5A,B1,C1). Hypoxia (15 and 10\%) significantly increased basal $\mathrm{f}_{\mathrm{R}}, \mathrm{V}_{\mathrm{T}}$, and MV $(p<0.0001, p=$ $0.029, p<0.0001$ for the effect of $\mathrm{O}_{2}$ on $\mathrm{f}_{\mathrm{R}}, \mathrm{V}_{\mathrm{T}}$, and MV, respectively, $N=7$ ), although the magnitude of these changes was smaller than those elicited by hypercapnia (Fig. 5 C1-C3). We observed a highly significant interaction between the ventilatory ment protocol.
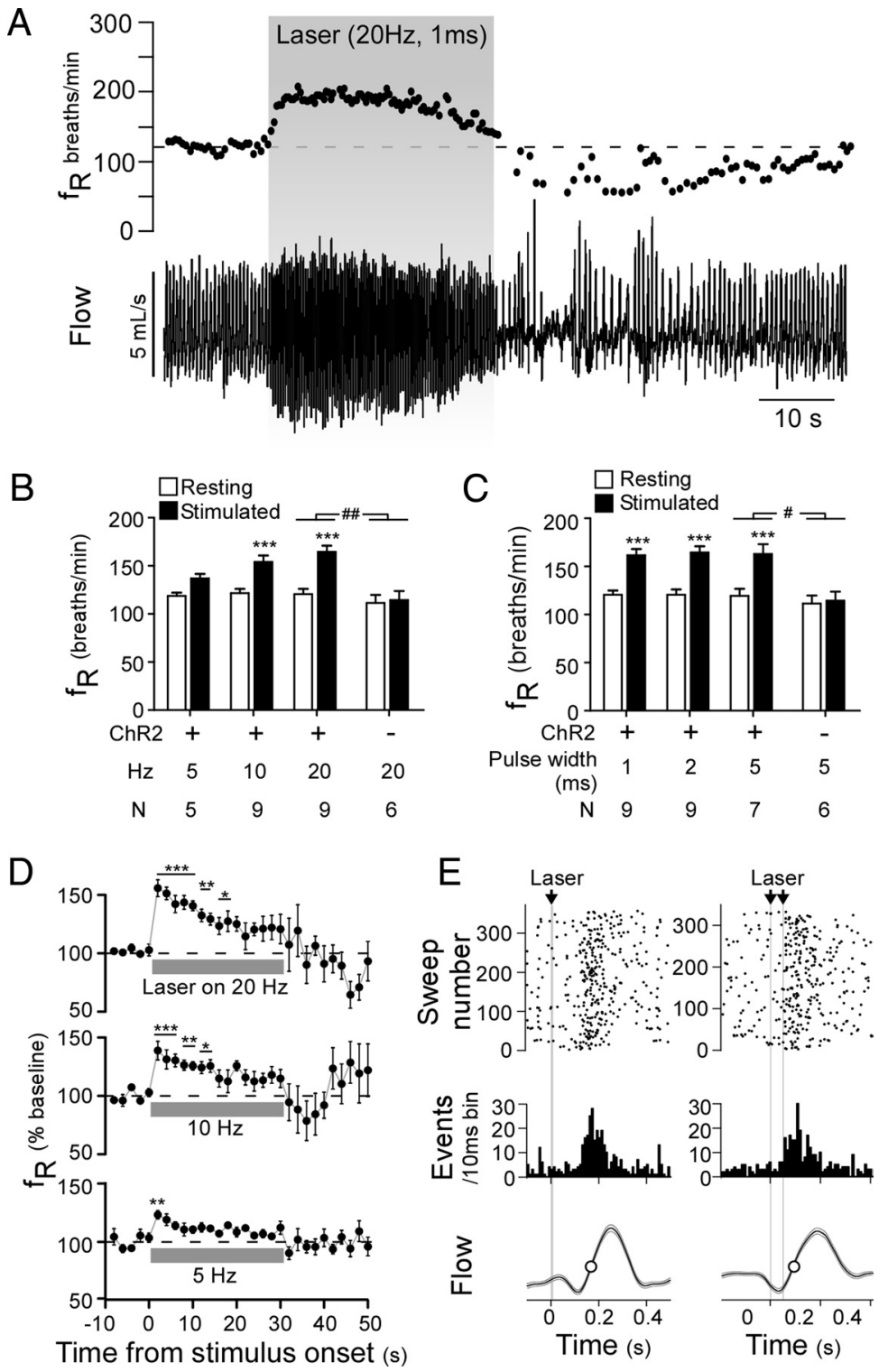

Figure 4. Optogenetic activation of ChR2-expressing RVLM-CA neurons activates breathing in conscious D $\beta \mathrm{H}^{\mathrm{Cr} / 0}$ mice. $A$, Plethysmography recording of the respiratory effects of photostimulation in an AAV2-DI0-EF1 $\alpha$-ChR2-mCherry-injected $D \beta H^{\text {Cre/0 }}$ mouse (top, respiratory frequency $\left(\mathrm{f}_{\mathrm{R}}\right)$; bottom, respiratory flow signal, upward deflection in waveform represents inspiration). $\boldsymbol{B}, \boldsymbol{C}$, Relationship between initial change in $\mathrm{f}_{\mathrm{R}}$ and stimulation frequency at constant light pulse duration (2 $\left.\mathrm{ms}\right)(\boldsymbol{B})$ and light pulse duration at constant stimulation frequency $(20 \mathrm{~Hz})(C)$ in experimental (ChR2-mCherry) and control mice (mCherry alone). ${ }^{* * *} p<0.001$ for resting versus stimulated in experimental mice by two-way ANOVA with multiple comparisons. ${ }^{*} p<$ $0.05,{ }^{\#} p<0.01$ for the interaction of ChR2-mcherry expression and stimulation in experimental versus control mice. D, Time course of the change in $f_{R}$ during $30 \mathrm{~s}$ stimulation trials at 20,10 , and $5 \mathrm{~Hz}$ with a 5 ms pulse width (top to bottom traces, respectively) $(N=7)$. $E$, Two examples of photostimulus-triggered histograms plotting the onset of inspiration relative to light pulses delivered at low frequency designed to entrain respiratory rhythm. Both the raster plot and binned event counts ( $10 \mathrm{~ms}$ bins) indicate that single (left, $10 \mathrm{~ms}$ pulse at $2 \mathrm{~Hz}$ ) and double (right, $5 \mathrm{~ms}$ pulses at $1.83 \mathrm{~Hz}$ ) light pulses produced a clustering of inspiratory events shortly after the stimulus. Lower trace, Photostimulus-triggered average of respiratory flow during the entrain-

effects of RVLM-CA neuron stimulation and hypoxia $(p<$ $0.0001, p=0.048, p<0.0001$ for $\mathrm{f}_{\mathrm{R}}, \mathrm{V}_{\mathrm{T}}$, and MV, respectively; two-way ANOVA). This interaction was completely occlusive, as no change in $\mathrm{f}_{\mathrm{R}}$ or $\mathrm{MV}$ was elicited by photostimulation when inspired oxygen was reduced to $10 \%$ (Fig. $5 \mathrm{~A}, \mathrm{C1}, \mathrm{C3}$ ).

Next, we compared the increase in $f_{R}$ during RVLM-CA neuron stimulation relative to resting $f_{R}$ under hypercapnic and hypoxic conditions using linear regression (Fig. $5 D$ ). This analysis revealed a significant inverse relationship between resting $f_{R}$ and the 
A

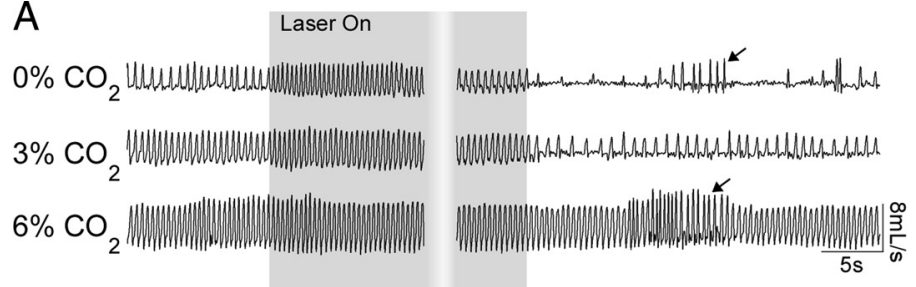

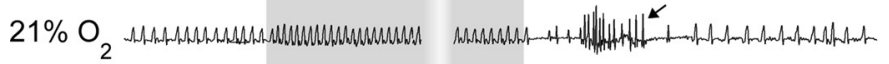

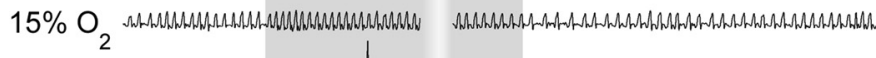

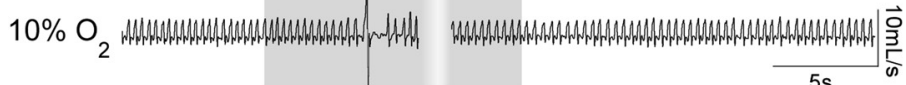

B1
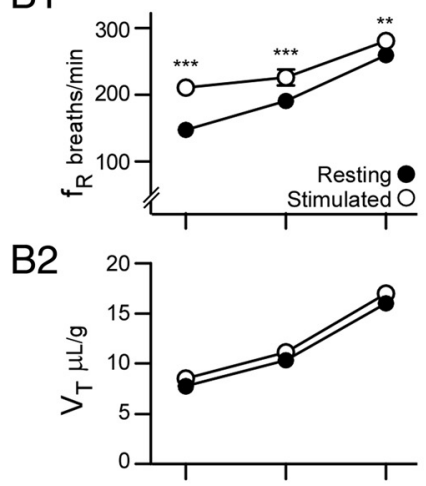

B3

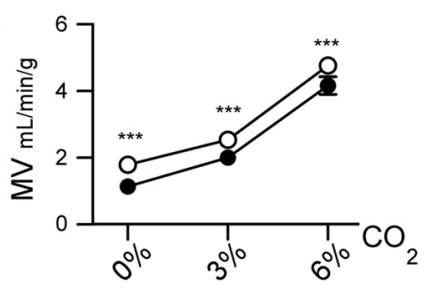

C1

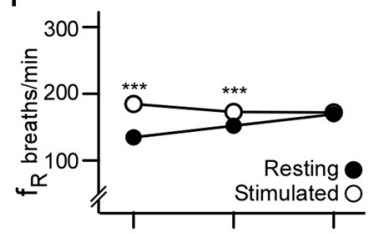

C2

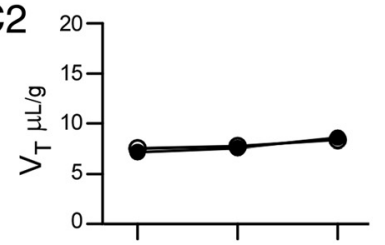

C3

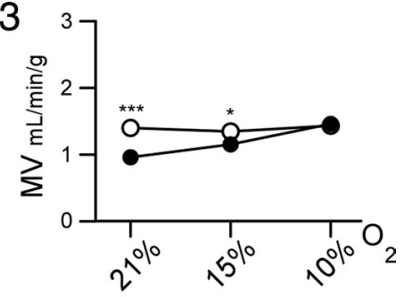

$\mathrm{E}$
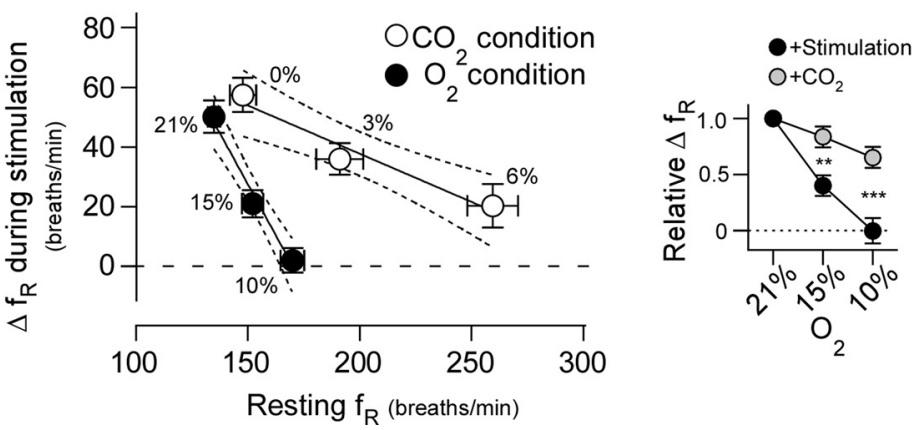

Figure 5. Changes in breathing frequency during stimulation of RVLM-CA neurons is differentially occluded by hypoxia and hypercapnia. $\boldsymbol{A}$, Initial respiratory effects of photostimulation $(5 \mathrm{~ms}$ pulse at $20 \mathrm{~Hz}$ for $30 \mathrm{~s})$ and poststimulus hypoventilation in a ChR2-mCherry-expressing D $\beta \mathrm{H}^{\text {Cre/0 }}$ mouse during hyperoxia ( $100 \% \mathrm{O}_{2}$, trace 1), hyperoxic hypercapnia ( 3 and $6 \% \mathrm{CO}_{2}$ balanced in $\mathrm{O}_{2}$, traces 2 and 3 , respectively), and a different mouse during normoxia $\left(21 \% \mathrm{O}_{2}\right.$ balanced in $\mathrm{N}_{2}$, trace 4$)$ and poikilocapnic hypoxia (15 and $10 \% \mathrm{O}_{2}$ balanced in $\mathrm{N}_{2}$, traces 5 and 6). Arrows identify bouts of poststimulus hyperventilation. Note that the period of hypoventilation following the offset of the stimulus under hyperoxic and normoxic conditions is largely abolished when respiratory drive is increased by activating the chemoreceptors. $\boldsymbol{B}$, Group data of the effects of photostimulation onf $f_{R}(\boldsymbol{B} 1), V_{T}(\boldsymbol{B} 2)$, and MV (B3) under hyperoxic and hyperoxic hypercapnic conditions. $N=9$ for each condition, ${ }^{*} p<0.05,{ }^{* *} p<0.01,{ }^{* * *} p<$ 0.001 for resting versus stimulated condition. $C$, Group data of the effects of photostimulation on $f_{R}(C 1), V_{T}(C 2)$, and MV (C3) under normoxic and hypoxic conditions. $N=7$ for each condition ${ }^{*} p<0.05,{ }^{* *} p<0.01$ for resting versus stimulated condition. $D, X-Y$ plot of the average change in $f_{R}$ during stimulation in relation to prestimulus $f_{R}$ under each gas mixture presented in $B 1$ and $\boldsymbol{C 1}\left(p=0.0001\right.$ for difference between slopes, hypercapnia $r^{2}=0.44$, hypoxia $r^{2}=0.73$; error bars indicate $\left.95 \% \mathrm{Cl}\right)$. $\boldsymbol{E}$, Change in $\mathrm{f}_{\mathrm{R}}$ caused by RVLM-CA neuron stimulation and a brief $\mathrm{CO}_{2}$ challenge ( $15 \mathrm{~s}$ of $\left.15 \% \mathrm{CO}_{2}\right)$ during graded hypoxia, normalized to the response $\mathrm{f}_{\mathrm{R}}$ under normoxic conditions. ${ }^{* *} p<0.01,{ }^{* * *} p<0.001$ for stimulation versus $\mathrm{CO}_{2}$ condition. light-induced increase in $\mathrm{f}_{\mathrm{R}}$ during hypoxia $(p<0.0001)$ and hypercapnia $(p=$ $0.0004)$. However, the slope of the regression was much steeper during hypoxia than during hypercapnia $(-1.37 \pm 0.19$ vs $-0.32 \pm 0.08, p=0.0001)$. This implies that the $\mathrm{f}_{\mathrm{R}}$ stimulation caused by RVLM-CA neuron activation is attenuated by hypoxia more than by hypercapnia despite a greater effect of hypercapnia on basal $f_{R}$ (Fig. $5 D$ ). To determine whether the attenuated effects of RVLM-CA neuron stimulation during hypoxia was caused by the depressive effects of central hypoxia on the respiratory network (Ballanyi, 2004; Funk et al., 2008), we tested the ability of a brief hypercapnic stimulus ( $15 \mathrm{~s}$ of $15 \% \mathrm{CO}_{2}$ ) to increase $\mathrm{f}_{\mathrm{R}}$ under normoxic and hypoxic conditions. This stimulus caused a transient increase in chamber $\mathrm{CO}_{2}$ (peak concentration: $4.1 \pm$ $0.1 \%)$ and transiently increased ventilation $\left(\mathrm{f}_{\mathrm{R}}:+101 \pm 8.7\right.$ breaths/min from baseline; $\mathrm{V}_{\mathrm{T}}:+4.5 \pm 1.1 \mu \mathrm{l} / \mathrm{g}$ from baseline; $\mathrm{MV}:$ $+1.8 \pm 0.23 \mathrm{ml} / \mathrm{g} / \mathrm{min}$ from baseline under normoxic conditions). The ventilatory effects of this stimulus was only marginally reduced under hypoxic conditions, in contrast to the effects of RVLM-CA neuron stimulation $(p=$ 0.048 for the interaction between $\mathrm{O}_{2}$ and stimulus type on the increase in $\mathrm{f}_{R}$ ) (Fig. $5 E)$. These results indicate that the occlusive effect of hypoxia on the respiratory effects of RVLM-CA neuron stimulation is not due to a hypoxia-related ceiling effect on ventilation.

\section{Activation of RVLM-CA neurons causes mixed cardiovascular effects in conscious normoxic mice}

The cardiovascular effects elicited by selective stimulation of RVLM-CA neurons are unknown, especially in conscious animals but, based on data obtained in anesthetized animals, a monotonic rise in BP, perhaps accompanied by a baroreflexmediated decrease in HR, would be expected (Guyenet, 2006). However, stimulating RVLM-CA neurons (six mice) produced very small changes in MBP and HR, tending toward a decrease in both parameters over the duration of a $30 \mathrm{~s}$ trial (Fig. 6A,D). Successful activation of RVLM-CA neurons was verified in all cases by the presence of the expected respiratory response (Fig. 6A). Although the absolute change in MBP and HR during stimulation were small, there was a distinct pattern change during the stimulus, namely an increased sinus arrhythmia (beat-to-beat HR variability linked to the breathing rate) (Fig. $6 A, B 1, B 2)$. Under resting conditions, the cardiac cycle was largely independent of the 
A

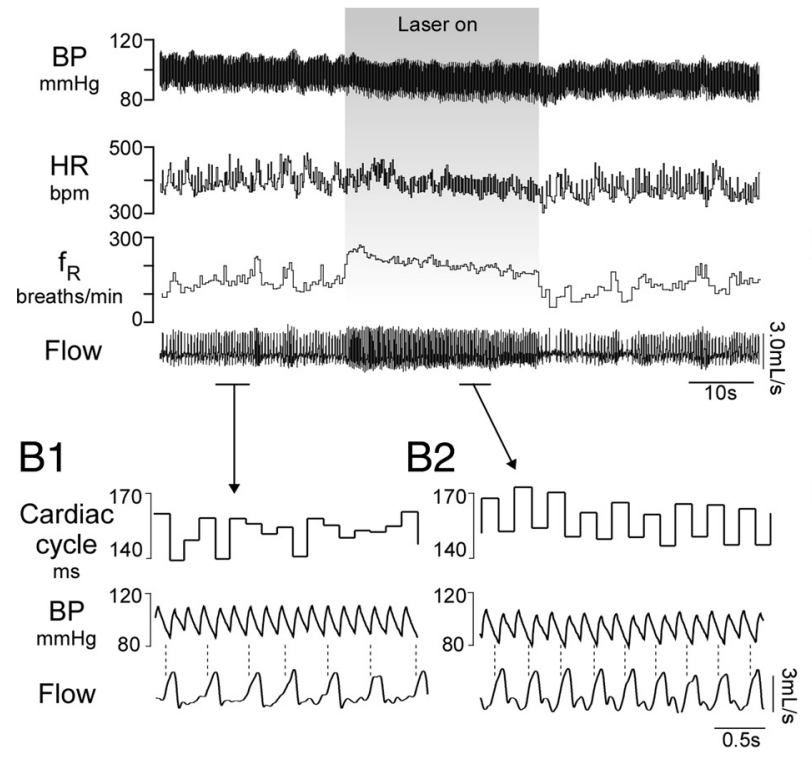

C

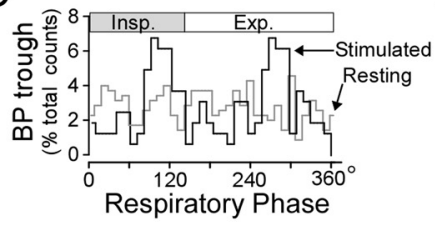

$\mathrm{E}$

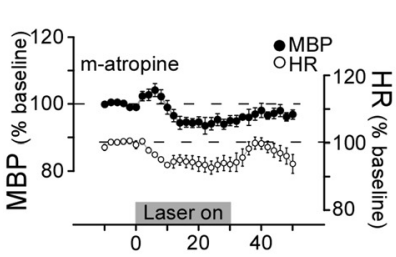

G

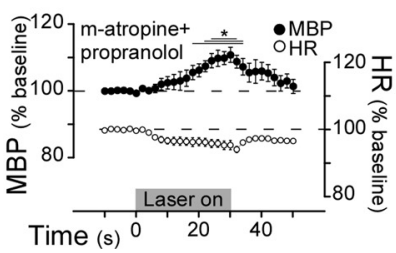

$\mathrm{D}$

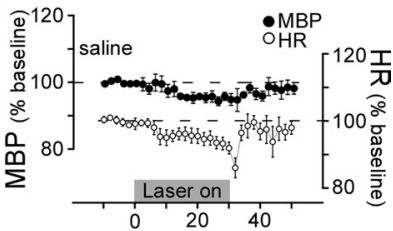

F

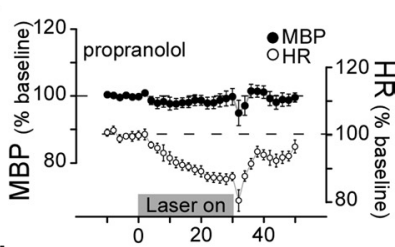

$\mathrm{H}$

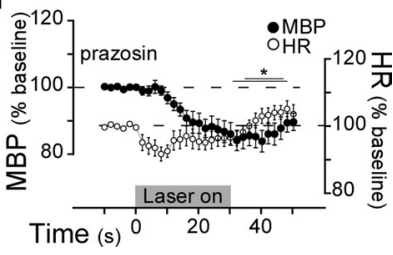

Figure 6. Selective activation of RVLM-CA neurons increases cardiorespiratory coupling and autonomic activation in conscious D $\beta H^{\text {Cre/0 }}$ mice. $A$, Cardiovascular and respiratory effects of RVLM-CA neuron stimulation (5 ms pulse at $20 \mathrm{~Hz}$ ). BP, arterial blood pressure; $\mathrm{HR}$, heart rate. $\boldsymbol{B 1}, \mathbf{B 2}$, Expanded traces of resting (B1) and stimulated (B2) segments in $\boldsymbol{A}$. During stimulation a marked increase in the synchronicity of the cardiac and respiratory cycles (sinus arrhythmia) is manifested by increased beat-to-beat variability. Broken vertical lines mark onset of inspiration and highlight sinus arrhythmia. C, Phase histogram plot of occurrence of BP nadirs (representing cardiac contraction) relative to the respiratory cycle (triggered from the rising phase of inspiration) plotted from $\boldsymbol{A}$. Note that while the respiratory cycle was shortened by stimulation, the phase duration of inspiration was unchanged (resting, $\mathbf{0}-130^{\circ} ;$ stimulated, $\left.\mathbf{O}-137^{\circ}\right)$. $\mathbf{D}-\boldsymbol{H}, \mathbf{E f f e c t s}$ of photostimulation $(5 \mathrm{~ms}, 20 \mathrm{~Hz}, 30 \mathrm{~s})$ on MBP and HR after intraperitoneal injection of saline $(\boldsymbol{D})$, methyl-atropine $(\boldsymbol{E})$, propranolol $(\boldsymbol{F})$, methyl-atropine plus propranolol $(\boldsymbol{G})$, and prazosin $(\boldsymbol{H})$. ( ${ }^{*} 0$ verlapping lines reflect significant differences: one line, $p<0.05$; two lines $p<0.01$; three lines $p<0.001$ by Dunnett's post test between drug and saline treatment.)

breathing cycle, as judged by the fact that the BP nadirs (i.e., heart beats) showed no apparent phase preference in the respiratory cycle (Fig. $6 B 1, C)$. In contrast, during periods of stimulation there was a clear synchrony between $B P$ nadirs and the respiratory cycle in a 2:1 ratio (Fig. 6B1,B2,C). In six animals, stimulation increased the respiratory phase amplitude of $\mathrm{BP}$ nadir events by $63 \%$ (resting vs stimulated: $3.6 \pm 1.4 \%$ vs $5.9 \pm 1.3 \%$ difference between the peak and trough of normalized $30^{\circ}$ bin counts, $p=0.038$ ). These results (increased sinus arrhythmia combined with modest drops in BP, i.e., despite reduced arterial baroreceptor activity) were observed in all mice and suggest that RVLM-CA stimulation might produce coactivation of the cardiovagal and sympathetic outflows. The next experiments were designed to test this possibility using a pharmacological approach.

First, we administered a selective muscarinic receptor antagonist, methyl-atropine, and a nonselective $\beta$-adrenoreceptor antagonist, propranolol, separately or together to block the neural control of the heart (Fig. $6 E-G$ ). Methyl-atropine alone significantly increased HR as expected and had no effect on MBP and $f_{R}$ (Table 2). Propranolol alone significantly increased MBP, possibly by interfering with the vasodilatory effect of adrenaline, and reduced $f_{R}$, with no change in HR. Neither methyl-atropine nor propranolol treatment significantly affected the change in MBP, $\mathrm{HR}$, and $\mathrm{f}_{\mathrm{R}}$ during photostimulation. In contrast, coadministration of methyl-atropine and propranolol (to block the neural control of the heart) uncovered a slowly developing pressor response during stimulation, with peak effects at the end of the stimulus (saline vs drugs: $-4.4 \pm 1.1$ vs $9.7 \pm$ $2.2 \mathrm{mmHg}$ change from baseline, $p<0.001$ ) (Fig. $6 G$ ). This drug combination did not significantly alter the effects of RVLM-CA neuron stimulation on $f_{R}$ or $H R$ relative to treatment with saline, but increased resting MBP (Table 2). The increase in BP elicited by RVLM-CA neuron stimulation in the combined presence of a $\beta$-adrenergic and a muscarinic antagonist implies that a degree of
Table 2. Basal mean arterial pressure, heart rate, and breathing frequency following intraperitoneal injection of pharmacological agents

\begin{tabular}{|c|c|c|c|}
\hline & $\begin{array}{l}\text { Mean arterial } \\
\text { pressure }(\mathrm{mmHg})\end{array}$ & Heart rate (bpm) & $\begin{array}{l}\text { Respiratory } \\
\text { frequency } \\
\text { (breaths/min) }\end{array}$ \\
\hline & Baseline & Baseline & Baseline \\
\hline Control & $88.9 \pm 5.3$ & $380.4 \pm 16.1$ & $141.1 \pm 5.6$ \\
\hline Saline & $92.7 \pm 4.6$ & $388.9 \pm 31.0$ & $132.3 \pm 8.2$ \\
\hline m-Atropine & $99.5 \pm 5.0$ & $546.8 \pm 25.7^{* * *}$ & $155.1 \pm 7.3$ \\
\hline Propranolol & $108.7 \pm 7.2^{*}$ & $351.1 \pm 31.0$ & $107.2 \pm 2.2^{*}$ \\
\hline m-Atropine + Propranolol & $109.9 \pm 7.8^{*}$ & $360.3 \pm 30.7$ & $140.0 \pm 19.0$ \\
\hline Prazosin & $76.7 \pm 5.7$ & $535.1 \pm 41.3^{* * *}$ & $139.0 \pm 5.9$ \\
\hline
\end{tabular}

Results analyzed by one-way ANOVA repeated measures with Dunnett's multiple-comparison tests. ${ }^{*} p<0.05$ ${ }^{* * *} p<0.001$ versus control values.

sympathetic vasoconstriction occurs during photostimulation. To test this possibility further we administered the $\alpha 1$-adrenergic receptor antagonist prazosin. This drug did not significantly reduce MBP and $\mathrm{f}_{\mathrm{R}}$, but caused an increase in resting $\mathrm{HR}(p<0.001)$ (Table 2). In the presence of prazosin, RVLM-CA neuron photostimulation produced a slowly developing hypotension that was greater than in saline-injected trials $(-4.4 \pm 1.3 \mathrm{vs}-9.4 \pm 2.2 \mathrm{mmHg}$ change from baseline, $p=0.0345$ ) (Fig. $6 H$ ). Together, these results show that selective activation of RVLM-CA neurons causes $\alpha 1$-adrenergic receptor-mediated vasoconstriction, presumably via the release of catecholamines by sympathetic nerves. More importantly, we provide evidence that RVLM-CA neurons control the circulation by coactivating the sympathetic and parasympathetic divisions of the autonomic nervous system.

\section{Brain regions targeted by ChR2-expressing RVLM-CA neurons}

These last experiments were designed to identify the CNS regions that could mediate the breathing and cardiovascular stimulation 
produced by activating the RVLM-CA neurons. As shown previously using the same experimental model, the vast majority of mCherry-labeled axonal varicosities and boutons are immunoreactive for both TH and VGLUT2 (Depuy et al., 2013). VGLUT2 immunoreactivity is no longer observable in these varicosities when the same AAV2 vector is injected into the RVLM of $\mathrm{D} \beta \mathrm{H}^{\mathrm{Cre} / 0}$;VGLUT2 ${ }^{\text {flox/flox }}$ mice in which VGLUT2 should be selectively deleted. Accordingly, as in rats, many mouse RVLM-CA neurons are also glutamatergic. Since the presence of VGLUT2 denotes the existence of an excitatory synapse (Fremeau et al., 2001), we mapped the brain distribution of the mCherry-labeled axonal varicosities that also express VGLUT2 immunoreactivity as a first-pass approximation of the regions where the transduced RVLM-CA neurons establish excitatory synapses. The list of innervated regions largely recapitulates the observations of Card et al. (2006) in the rat.

The following description focuses on the regions where the transduced RVLM-CA neurons could most plausibly have stimulated breathing and the cardiovascular system. Transduced catecholaminergic neurons had putative glutamatergic terminals within every pontomedullary region that harbors noradrenergic neurons including the locus ceruleus (Fig. $7 D, L$ ), A1 (Fig. $7 A, K)$, A2 (Fig. $7 B$ ), and $\mathrm{A} 5$ region (Fig. $7 D$ ). The lateral parabrachial nucleus was heavily targeted (Fig. $7 D, E, O, P$ ), but other pontine regions implicated in respiratory control (Kölliker-Fuse nucleus and intertrigeminal region) received no input from the transduced RVLM-CA neurons (Fig. $7 D, E$ ). We observed light projections within the medullary raphe, a region also noted for its role in respiratory control (Hodges and Richerson, 2010; Depuy et al., 2011); moderately dense projections to the nucleus of the solitary tract, which receives input from the carotid bodies and other cardiopulmonary afferents (Kubin et al., 2006); and extremely dense projections to the dorsal motor nucleus of the vagus (Fig. $7 A$ ). In the hypothalamus, heavy projections were identified within the dorsomedial nucleus and the lateral hypothalamic region, which contains orexinergic neurons (Fig. $7 F$ ). Heavy projections to the paraventricular nucleus (Fig. $7 G$ ) previously described in rats, e.g., (Card et al., 2006), were also observed in these mice although the role of this nucleus in breathing control is not clearly established. Dense projections to the paraventricular thalamic nucleus were also detected (Fig. $7 F, G$ ), consistent with prior evidence in rats (Hokfelt et al., 1974; Card et al., 2006). This nucleus is suspected to contribute to arousal and attention and stress responses (Li and Kirouac, 2012).

All projections had a strong ipsilateral predominance. The RTN was targeted on both sides (Fig. $7 C, M, N$ ) but, ipsilaterally, these superficial projections encompassed the ventral medullary surface as far caudal as the lateral reticular nucleus, i.e., distinctly caudal to the area that harbors the RTN-defining Phox2b neurons of mice (Lazarenko et al., 2009). The superficial region of the ventrolateral medulla contains the distal dendrites of respiratory neurons implicated in respiratory rhythm generation and could conceivably represent a site of interaction between the RVLM-CA neurons and the respiratory pattern generator (Spyer and Gourine, 2009). The RVLM-CA neurons of the mouse did not innervate the ventral horn of the spinal cord and readily identifiable lower brainstem motor neurons (facial, hypoglossal, trigeminal) were not targeted consistent with distribution of PNMT immunoreactivity in other species. Finally, the spinal projections of the RVLM-CA neurons in the $\mathrm{D} \beta \mathrm{H}^{\mathrm{Cre} / 0}$ mouse were confined to the intermediolateral cell column and lamina 10 as expected (Fig. $7 H-J)$.

\section{Discussion}

This is the first description of the cardiorespiratory effects produced by selective activation of RVLM-CA neurons in a conscious animal. We show that these neurons regulate breathing and provide evidence that they may contribute to the hypoxic ventilatory reflex. We also provide evidence that RVLM-CA activation produces a complex cardiovascular response, including coactivation of the sympathetic and cardiovagal outflows.

\section{ChR2-expressing neurons were likely $\mathrm{C} 1$ cells}

As shown previously (Stornetta et al., 2012), most neurons that expressed ChR2-mCherry ( 99\%) were demonstrably catecholaminergic. The transduced catecholaminergic neurons were likely $\mathrm{C} 1$ (adrenergic) rather than A1 (noradrenergic) neurons for three reasons. Although we could not identify PNMT, the C1 cell-defining enzyme (Hokfelt et al., 1974), the ChR2positive neurons were restricted to a ventrolateral medullary region in which virtually every TH-ir cell expresses PNMT in five other species (Reiner and Vincent, 1986; Arango et al., 1988; Ruggiero et al., 1992; Dormer et al., 1993; Card et al., 2006). Second, as in rats, mouse RVLM-CA neurons commonly expressed VGLUT2 (Stornetta et al., 2002; Depuy et al., 2013). Finally, the RVLM-CA projections described here replicate the projections of the $\mathrm{C} 1$ cells in the rat (Card et al., 2006).

\section{RVLM-CA neurons activate breathing}

In anesthetized mice, RVLM-CA cell photostimulation modestly increased both diaphragmatic frequency and burst amplitude. In conscious mice, the respiratory changes produced by RVLM-CA cell stimulation and by hypoxia were similar (primarily $f_{R}$ increase) and distinctly different from those produced by hypercapnia (increased $f_{R}$ and $V_{T}$ ). Tidal volume is difficult to measure accurately in mice using unrestrained whole-body plethysmography. Therefore the most conservative interpretation is that RVLM-CA neurons increased $V_{T}$, but distinctly less than hypercapnia.

The breathing response elicited by photostimulation declined during the stimulation period and was followed by hypopnea. Based on recordings of ChR2-expressing C1 neurons in rats, the initial decline is probably not caused by the gradual loss of the cells' entrainment to the light pulses (Abbott et al., 2009b). Other possibilities include the gradual release of inhibitory neuromodulators from RVLM-CA neurons (e.g., catecholamines). However, because the initial frequency decline and the poststimulus hypopnea were both greatly attenuated by hypercapnia, these phenomena are more likely caused by the progressive reduction in central chemoreceptor drive due to hyperventilation.

We found that the respiratory effects of RVLM-CA neuron photostimulation were occluded under hypoxic conditions. The occlusion cannot be explained by the existence of a ceiling breathing frequency imposed by hypoxia or by CNS hypoxic depression of the respiratory network (Ballanyi, 2004; Funk et al., 2008) because $f_{R}$ could still be greatly increased by adding $\mathrm{CO}_{2}$. This occlusion most likely occurred at the level of the RVLM-CA neurons because, based on unit recording and Fos expression studies, many of these neurons are strongly activated by hypoxia (up to 30 Hz) (Erickson and Millhorn, 1994; Sun and Reis, 1996; Teppema et al., 1997). The hypoxic sensitivity of RVLM-CA neurons may be relayed by a direct input from the caudal nucleus tractus solitarius (NTS), which relays carotid body afferents (Chitravanshi and Sapru, 1995; Aicher et al., 1996; Sun, 1996). It stands to reason that optogenetic stimulation of RVLM-CA neurons at 20 
A

B

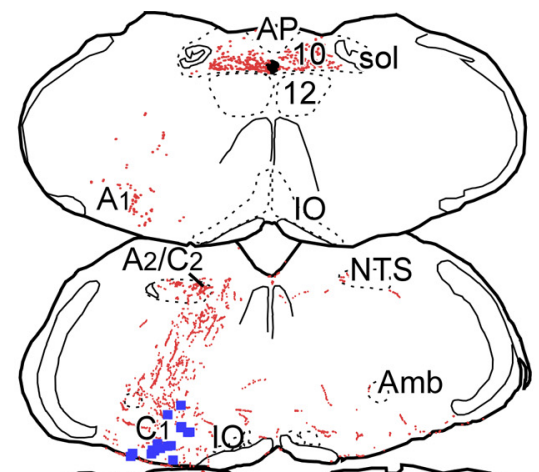

C

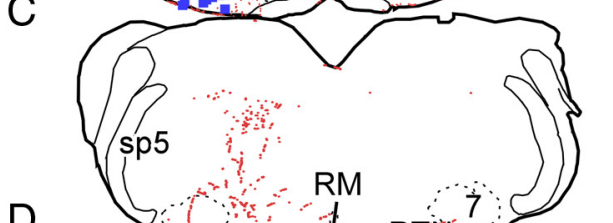

D
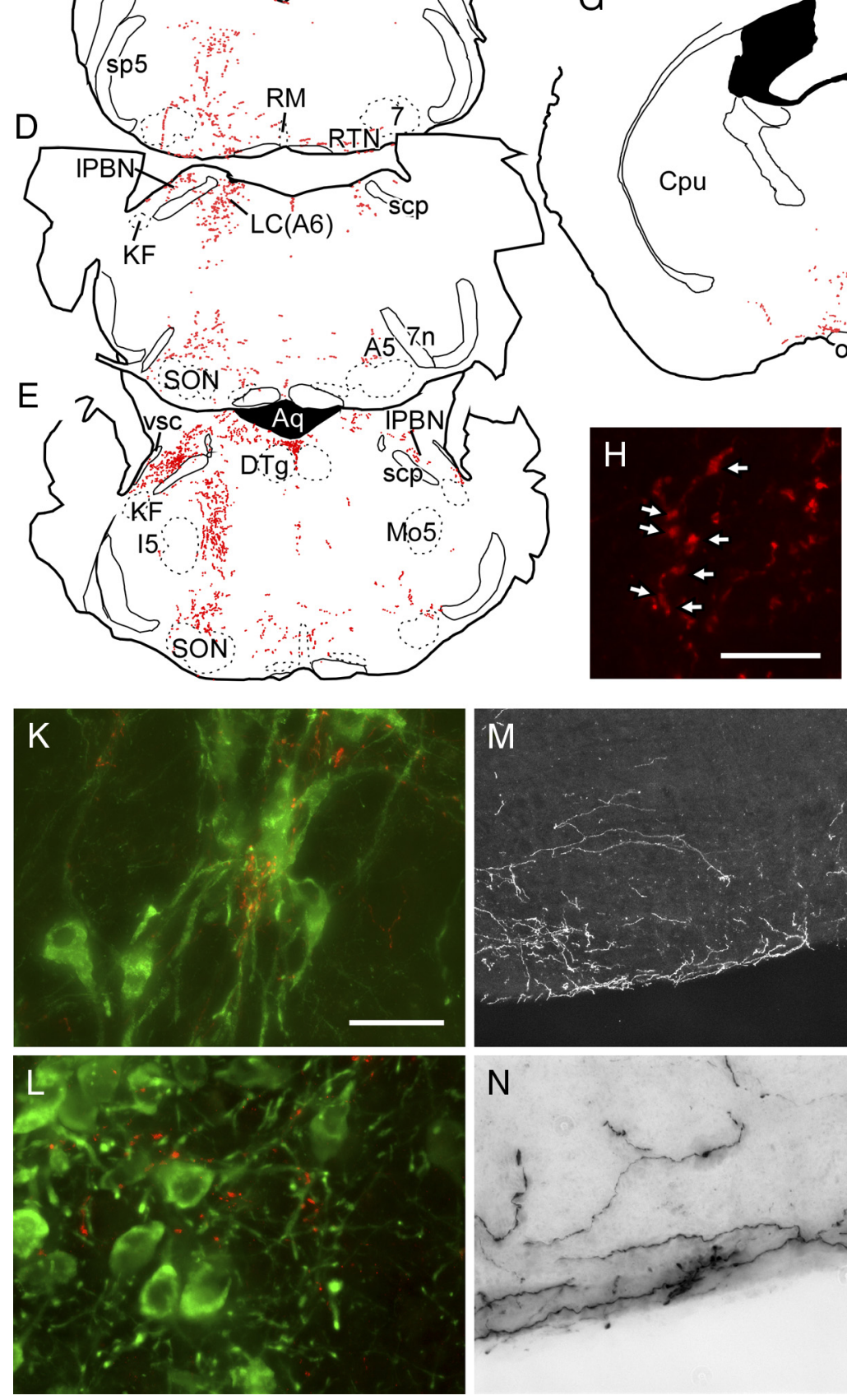

$\mathrm{F}$

$\mathrm{N}$
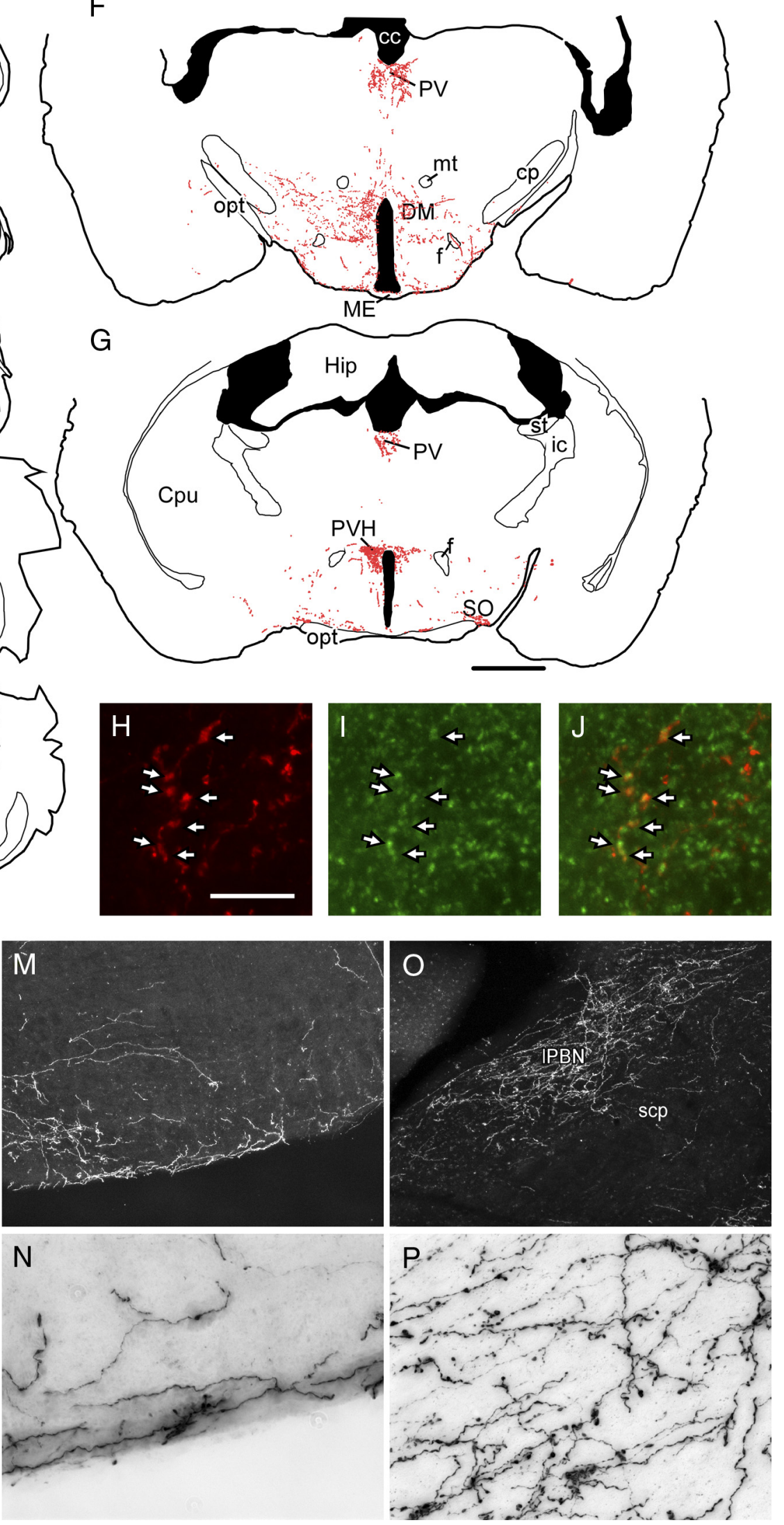

Figure 7. Glutamatergic projections of RVLM-CA neurons in $D \beta H^{\text {Cre/0 }}$ mice. $A-G$, Computer-assisted drawings of representative transverse brain sections from a $D \beta H^{C r e / 0}$ mouse in which RVLM-CA neurons expressed ChR2-mCherry. $\boldsymbol{B}$, At the level of the injection site, each blue square represents a single mCherry-expressing TH-ir neuron. Each red dot represents a putative synaptic terminal ir for both VGLUT2 and mCherry. The AAV2 vector was injected on the left and all drawings retain this orientation. Estimated distance in millimeters caudal to bregma in $\boldsymbol{A}, 7.76 ; \boldsymbol{B}, 6.72 ; \boldsymbol{C}$, $6.36 ; \boldsymbol{D}, 5.34 ; \boldsymbol{E}, 5.20 ; \boldsymbol{F}, 1.94 ; \boldsymbol{G}, 0.82$. $\boldsymbol{H}-\boldsymbol{J}$, Coronal section of the thoracic spinal cord showing mCherry-ir terminals $(\boldsymbol{H})$ and VGlut2-ir terminals (I) (Figure legend continues.) 
$\mathrm{Hz}$ when these cells are already extremely activated should produce little additional increase in overall firing, hence the occlusive interaction with hypoxia. In contrast RVLM-CA neurons are very moderately activated by hypercapnia (Erickson and Millhorn, 1994; Moreira et al., 2006), therefore the same reasoning would predict a much milder interaction between hypercapnia and photostimulation, as was found. In short, subsets of RVLM-CA neurons are capable of driving the respiratory network and the cells that do so are probably highly responsive to hypoxia. The logical consequence is that subsets of RVLM-CA neurons contribute to the hypoxic ventilatory reflex.

In contrast, the modest interaction between RVLM-CA neuron stimulation and hypercapnia suggests that these neurons are unlikely to have a critical role in the hypercapnic ventilatory response. Indeed, this response is largely attributed to other neuronal groups such as the RTN, locus ceruleus, and serotonergic and orexinergic neurons (Biancardi et al., 2008; Hodges et al., 2008; Guyenet et al., 2010; Nattie and Li, 2010). Interestingly, lesions of three of these groups (RTN excepted) produced no effect on the hypoxic ventilatory response (Biancardi et al., 2008; Hodges et al., 2008; Kuwaki, 2010).

The RVLM-CA neurons could plausibly activate breathing by activating the RTN (Card et al., 2006; Guyenet et al., 2010), the lateral parabrachial region (Chamberlin, 2004), or the NTS (Sapru, 1996). Respiratory rhythm-generating neurons located in the pre-Bötzinger complex could also receive direct input from the RVLM-CA neurons via their distal dendrites (Pilowsky et al., 1990; Spyer and Gourine, 2009). Theoretically, RVLM-CA neurons could also increase breathing via arousal since these neurons innervate relevant wake-promoting regions (e.g., dorsal parabrachial region, locus coeruleus, dorsomedial hypothalamic nucleus, perifornical region) (Aston-Jones et al., 2001; DiMicco et al., 2002; Kuwaki, 2010). However, the persistence of the respiratory effect of RVLM-CA neuron stimulation under anesthesia and the instantaneous nature of the breathing stimulation in the conscious mouse argue against a primary role of arousal in the respiratory responses observed presently.

\section{Cardiovascular effects of RVLM-CA neuron stimulation}

The regulation of sympathetic vasomotor tone and BP is the most recognized function of the RVLM (Guyenet, 2006), therefore it seems counterintuitive that RVLM-CA neuron stimulation

\section{$\leftarrow$}

(Figure legend continued.) (merged image in $\boldsymbol{J}$ ) in the intermediolateral cell column. Arrows show coincidence of these markers, indicating that the mCherry-expressing RVLM-CA neurons are glutamatergic. $\boldsymbol{K}, \boldsymbol{L}$, mCherry-ir fibers and terminals (Cy3, red) making close appositions with TH-ir (Alexa 488, green) A1neurons ( $\boldsymbol{K}$ ) and locus ceruleus neurons ( $\boldsymbol{L}$ ). $\boldsymbol{M}, \boldsymbol{N}$, mCherry immunoreactivity visualized with DAB chromagen on the ventral surface of the RVLM on the side contralateral to the injection site. $\boldsymbol{M}$, Dark field (low power) and $\boldsymbol{N}$, bright field (high power). $\mathbf{0}-\boldsymbol{P}, \mathrm{mCherry}$ immunoreactivity in the lateral parabrachial nucleus visualized with DAB chromagen (side ipsilateral to the injection). $\boldsymbol{O}$, Dark field (low power) and $\boldsymbol{P}$, bright field (high power). Scale bars: (in $\boldsymbol{G}) \boldsymbol{A}-\boldsymbol{G}, 1 \mathrm{~mm}$; (in $\boldsymbol{H}) \boldsymbol{H}-\boldsymbol{J}, 10 \mu \mathrm{m}$; (in $\boldsymbol{K}) \boldsymbol{K}, \boldsymbol{L}, \boldsymbol{N}, \boldsymbol{P}, 30 \mu \mathrm{m}, \boldsymbol{M}, \mathbf{0}$, $190 \mu \mathrm{m} .7$, Facial motor nucleus; $7 \mathrm{n}$, facial nerve; 10, dorsal motor nucleus of the vagus; 12, hypoglossal nucleus; $\mathrm{A1}$, A1 noradrenergic cell cluster; $\mathrm{A2} / \mathrm{C} 2$, dorsal medullary noradrenergic and adrenergic cell clusters; A5, A5 pontine noradrenergic cell cluster; Aq, aqueduct of Sylvius; cc, corpus callosum; $c p$, cerebellar peduncle, basal part; (Pu, caudate-putamen; DM, dorsomedial hypothalamic nucleus; DTg, dorsal tegmental nucleus; f, fornix; Hip, hippocampus; 15 , intertrigeminal nucleus; ic, internal capsule; KF, Kölliker-Fuse nucleus; LC, locus coeruleus; IPBN, lateral parabrachial nucleus; $\mathrm{ME}$, median eminence; $\mathrm{Mo5}$, motor trigeminal nucleus; $\mathrm{mt}$, mammillothalamic tract; opt, optic tract; PV, paraventricular thalamic nucleus; $\mathrm{PVH}$, paraventricular hypothalamic nucleus; RM, raphe magnus; scp, superior cerebellar peduncle; $\mathrm{sp5}$, spinal trigeminal tract; $\mathrm{SO}$, supraoptic nucleus; $\mathrm{SON}$, superior olive; sol, solitary tract; st, stria terminalis; vsc, ventral spinocerebellar tract. would not increase BP in conscious mice. A possible explanation is the functional heterogeneity of the RVLM-CA neurons and the high probability that we activated a heterogeneous collection of these cells. Prior work in rats has largely focused on the rostral tip of the RVLM, which contains the subset of C1 neurons (approximately a third) that have spinal projections and are presumed to be sympathoexcitatory. This particular subset may itself be functionally heterogeneous (McAllen et al., 1995; Guyenet, 2006). More importantly perhaps, RVLM-CA neurons are interspersed with a substantial population of bulbospinal sympathoexcitatory neurons that are not catecholaminergic (thus not stimulated in the current study) and could very well be the key players in the sympathetic control of BP (Lipski et al., 1995; Schreihofer and Guyenet, 1997). Finally, the function of the caudal two-thirds of the RVLM-CA cells is largely unexplored from a cardiorespiratory standpoint except for the fact that the region may contain bulbospinal $\mathrm{C} 1$ neurons that selectively regulate adrenal epinephrine release (Ritter et al., 1998; Cao and Morrison, 2001).

The cardiovascular response produced by RVLM-CA neuron stimulation is best explained by the coactivation of various sympathetic and cardiovagal efferents. The anticipated $\alpha 1$-adrenergic sympathetic vasoconstrictor response to RVLM-CA neurons was only revealed following autonomic blockade of the heart (propranolol and atropine). It was confirmed by the existence of an exaggerated depressor response to $\alpha 1$-adrenergic blockade (prazosin) but was altogether surprisingly modest. In drug-free mice, $\alpha 1$-mediated vasoconstriction was obscured by the bradycardia and, perhaps, by $\beta 2$-mediated muscle vasodilation (propranololsensitive) resulting from adrenaline release (Ritter et al., 1998; Cao and Morrison, 2001). The bradycardia, which tended to increase after $\beta$-blockade, as well as the increase in sinus arrhythmia, are consistent with cardiovagal stimulation. Neither the bradycardia nor the sinus arrhythmia was driven by the baroreflex because BP decreased during stimulation. Since $V_{T}$ barely changed, increased vagal pulmonary afferent discharge presumably did not cause the sinus arrhythmia either. Therefore, the most likely explanation for the facilitated sinus arrhythmia is an increased central coupling between the respiratory network and cardiovagal efferents. Parasympathetic system activation by subsets of RVLM-CA neurons is consistent with their massive projection to the dorsal motor nucleus of the vagus and evidence that this projection has a glutamatergic component (Depuy et al., 2013).

The results presented here imply that activation of RVLM-CA neurons recruits sympathetic and parasympathetic drive to the heart. Coactivation of cardiovagal and sympathetic efferents occurs in response to peripheral chemoreceptor stimulation and diving (Kollai et al., 1978; Koizumi et al., 1982; Paton et al., 2005). It improves the efficiency (Koizumi et al., 1983) and reduces the metabolic cost (Vimercati et al., 2012) of blood pumping during periods of high sympathetic drive to the heart. Sinus arrhythmia is also thought to minimize cardiac work (Hayano et al., 1996; Ben-Tal et al., 2012).

\section{Conclusion}

In this study we presumably activated several functional subsets of $\mathrm{C} 1$ cells. The resulting cardiorespiratory response pattern should not be considered strictly "physiological," because a physiological response is never initiated by selective activation of a single cluster of CNS neurons and the various subsets of $\mathrm{C} 1$ neurons are presumably never recruited en bloc under any physiological condition. This caveat applies to most optogenetic experiments in which ChR2 expression is based on a particular 
genetic marker. What our experiments reveal is a range of potential cardiorespiratory responses that may occur when one or more subsets of RVLM-CA cells are activated. Presently, the experiments reveal two novel effects of the RVLM-CA neurons, namely respiratory stimulation and cardiovagal activation. These effects likely contribute to the baro-respiratory reflex (McMullan and Pilowsky, 2010), the hypoxic ventilatory reflex, and, possibly, respiratory stimulation evoked by nociceptive stimuli (Sun and Spyer, 1991a).

\section{References}

Abbott SB, Stornetta RL, Fortuna MG, Depuy SD, West GH, Harris TE, Guyenet PG (2009a) Photostimulation of retrotrapezoid nucleus phox $2 \mathrm{~b}$-expressing neurons in vivo produces long-lasting activation of breathing in rats. J Neurosci 29:5806-5819. CrossRef Medline

Abbott SB, Stornetta RL, Socolovsky CS, West GH, Guyenet PG (2009b) Photostimulation of channelrhodopsin-2 expressing ventrolateral medullary neurons increases sympathetic nerve activity and blood pressure in rats. J Physiol 587:5613-5631. CrossRef Medline

Abbott SB, Stornetta RL, Coates MB, Guyenet PG (2011) Phox2bexpressing neurons of the parafacial region regulate breathing rate, inspiration, and expiration in conscious rats. J Neurosci 31:16410-16422. CrossRef Medline

Aicher SA, Saravay RH, Cravo S, Jeske I, Morrison SF, Reis DJ, Milner TA (1996) Monosynaptic projections from the nucleus tractus solitarii to C1 adrenergic neurons in the rostral ventrolateral medulla: comparison with input from the caudal ventrolateral medulla. J Comp Neurol 373:62-75. CrossRef Medline

Arango V, Ruggiero DA, Callaway JL, Anwar M, Mann JJ, Reis DJ (1988) Catecholaminergic neurons in the ventrolateral medulla and nucleus of the solitary tract in the human. J Comp Neurol 273:224-240. CrossRef Medline

Aston-Jones G, Chen S, Zhu Y, Oshinsky ML (2001) A neural circuit for circadian regulation of arousal. Nat Neurosci 4:732-738. CrossRef Medline

Ballanyi K (2004) Protective role of neuronal KATP channels in brain hypoxia. J Exp Biol 207:3201-3212. CrossRef Medline

Ben-Tal A, Shamailov SS, Paton JF (2012) Evaluating the physiological significance of respiratory sinus arrhythmia: looking beyond ventilationperfusion efficiency. J Physiol 590:1989-2008. CrossRef Medline

Biancardi V, Bícego KC, Almeida MC, Gargaglioni LH (2008) Locus coeruleus noradrenergic neurons and $\mathrm{CO} 2$ drive to breathing. Pflugers Arch 455:1119-1128. CrossRef Medline

Brown DL, Guyenet PG (1985) Electrophysiological study of cardiovascular neurons in the rostral ventrolateral medulla in rats. Circ Res 56:359-369. CrossRef Medline

Butz GM, Davisson RL (2001) Long-term telemetric measurement of cardiovascular parameters in awake mice: a physiological genomics tool. Physiol Genomics 5:89-97. Medline

Cao WH, Morrison SF (2001) Differential chemoreceptor reflex responses of adrenal preganglionic neurons. Am J Physiol Regul Integr Comp Physiol 281:R1825-R1832. Medline

Card JP, Sved JC, Craig B, Raizada M, Vazquez J, Sved AF (2006) Efferent projections of rat rostroventrolateral medulla $\mathrm{Cl}$ catecholamine neurons: implications for the central control of cardiovascular regulation. J Comp Neurol 499:840-859. CrossRef Medline

Cardin JA, Carlén M, Meletis K, Knoblich U, Zhang F, Deisseroth K, Tsai LH, Moore CI (2009) Driving fast-spiking cells induces gamma rhythm and controls sensory responses. Nature 459:663-667. CrossRef Medline

Cardin JA, Carlén M, Meletis K, Knoblich U, Zhang F, Deisseroth K, Tsai LH, Moore CI (2010) Targeted optogenetic stimulation and recording of neurons in vivo using cell-type-specific expression of Channelrhodopsin-2. Nat Protoc 5:247-254. CrossRef Medline

Chamberlin NL (2004) Functional organization of the parabrachial complex and intertrigeminal region in the control of breathing. Respir Physiol Neurobiol 143:115-125. CrossRef Medline

Chamberlin NL, Saper CB (1992) Topographic organization of cardiovascular responses to electrical and glutamate microstimulation of the parabrachial nucleus in the rat. J Comp Neurol 326:245-262. CrossRef Medline

Chitravanshi VC, Sapru HN (1995) Chemoreceptor-sensitive neurons in commissural subnucleus of nucleus tractus solitarius of the rat. Am J Physiol 268:R851-R858. Medline

Depuy SD, Kanbar R, Coates MB, Stornetta RL, Guyenet PG (2011) Control of breathing by raphe obscurus serotonergic neurons in mice. J Neurosci 31:1981-1990. CrossRef Medline

Depuy SD, Stornetta RL, Bochorishvili G, Deisseroth K, Witten I, Coates MB, Guyenet PG (2013) Glutamatergic neurotransmission between the C1 neurons and the parasympathetic preganglionic neurons of the dorsal motor nucleus of the vagus. J Neurosci. 33:1486-1497. CrossRef Medline

DiMicco JA, Samuels BC, Zaretskaia MV, Zaretsky DV (2002) The dorsomedial hypothalamus and the response to stress: part renaissance, part revolution. Pharmacol Biochem Behav 71:469-480. CrossRef Medline

Dormer KJ, Anwar M, Ashlock SR, Ruggiero DA (1993) Organization of presumptive catecholamine-synthesizing neurons in the canine medullaoblongata. Brain Res 601:41-64. CrossRef Medline

Drorbaugh JE, Fenn WO (1955) A barometric method for measuring ventilation in newborn infants. Pediatrics 16:81-87. Medline

Erickson JT, Millhorn DE (1994) Hypoxia and electrical stimulation of the carotid sinus nerve induce c-Fos-like immunoreactivity within catecholaminergic and serotinergic neurons of the rat brainstem. J Comp Neurol 348:161-182. CrossRef Medline

Fremeau RT Jr, Troyer MD, Pahner I, Nygaard GO, Tran CH, Reimer RJ, Bellocchio EE, Fortin D, Storm-Mathisen J, Edwards RH (2001) The expression of vesicular glutamate transporters defines two classes of excitatory synapse. Neuron 31:247-260. CrossRef Medline

Funk GD, Huxtable AG, Lorier AR (2008) ATP in central respiratory control: a three-part signaling system. Respir Physiol Neurobiol 164:131-142. CrossRef Medline

Gong S, Zheng C, Doughty ML, Losos K, Didkovsky N, Schambra UB, Nowak NJ, Joyner A, Leblanc G, Hatten ME, Heintz N (2003) A gene expression atlas of the central nervous system based on bacterial artificial chromosomes. Nature 425:917-925. CrossRef Medline

Guyenet PG (2006) The sympathetic control of blood pressure. Nat Rev Neurosci 7:335-346. CrossRef Medline

Guyenet PG, Stornetta RL, Bayliss DA (2010) Central respiratory chemoreception. J Comp Neurol 518:3883-3906. CrossRef Medline

Hayano J, Yasuma F, Okada A, Mukai S, Fujinami T (1996) Respiratory sinus arrhythmia. A phenomenon improving pulmonary gas exchange and circulatory efficiency. Circulation 94:842-847. CrossRef Medline

Hirooka Y, Polson JW, Potts PD, Dampney RA (1997) Hypoxia-induced Fos expression in neurons projecting to the pressor region in the rostral ventrolateral medulla. Neuroscience 80:1209-1224. CrossRef Medline

Hodges MR, Richerson GB (2010) The role of medullary serotonin (5-HT) neurons in respiratory control: contributions to eupneic ventilation, $\mathrm{CO} 2$ chemoreception, and thermoregulation. J Appl Physiol 108:1425-1432. CrossRef Medline

Hodges MR, Tattersall GJ, Harris MB, McEvoy SD, Richerson DN, Deneris ES, Johnson RL, Chen ZF, Richerson GB (2008) Defects in breathing and thermoregulation in mice with near-complete absence of central serotonin neurons. J Neurosci 28:2495-2505. CrossRef Medline

Hokfelt T, Fuxe K, Goldstein M, Johansson O (1974) Immunohistochemical evidence for the existence of adrenaline neurons in the rat brain. Brain Res 66:235-251. CrossRef

Kang BJ, Chang DA, Mackay DD, West GH, Moreira TS, Takakura AC, Gwilt JM, Guyenet PG, Stornetta RL (2007) Central nervous system distribution of the transcription factor Phox $2 b$ in the adult rat. J Comp Neurol 503:627-641. CrossRef Medline

Koizumi K, Terui N, Kollai M, Brooks CM (1982) Functional significance of coactivation of vagal and sympathetic cardiac nerves. Proc Natl Acad Sci U S A 79:2116-2120. CrossRef Medline

Koizumi K, Terui N, Kollai M (1983) Neural control of the heart: significance of double innervation re-examined. J Auton Nerv Syst 7:279-294. CrossRef Medline

Kollai M, Koizumi K, Brooks CM (1978) Nature of differential sympathetic discharges in chemoreceptor reflexes. Proc Natl Acad Sci U S A 75:5239_ 5243 [LIBR]. CrossRef Medline

Kubin L, Alheid GF, Zuperku EJ, McCrimmon DR (2006) Central pathways of pulmonary and lower airway vagal afferents. J Appl Physiol 101:618627. CrossRef Medline

Kuwaki T (2010) Hypothalamic modulation of breathing. Adv Exp Med Biol 669:243-247. CrossRef Medline

Lazarenko RM, Milner TA, Depuy SD, Stornetta RL, West GH, Kievits JA, 
Bayliss DA, Guyenet PG (2009) Acid sensitivity and ultrastructure of the retrotrapezoid nucleus in Phox2b-EGFP transgenic mice. J Comp Neurol 517:69-86. CrossRef Medline

Li A, Nattie E (2010) Antagonism of rat orexin receptors by almorexant attenuates central chemoreception in wakefulness in the active period of the diurnal cycle. J Physiol 588:2935-2944. CrossRef Medline

Li AJ, Wang Q, Dinh TT, Ritter S (2009) Simultaneous silencing of Npy and Dbh expression in hindbrain A1/C1 catecholamine cells suppresses glucoprivic feeding. J Neurosci 29:280-287. CrossRef Medline

Li S, Kirouac GJ (2012) Sources of inputs to the anterior and posterior aspects of the paraventricular nucleus of the thalamus. Brain Struct Funct 217:257-273. CrossRef Medline

Lipski J, Kanjhan R, Kruszewska B, Smith M (1995) Barosensitive neurons in the rostral ventrolateral medulla of the rat in vivo: morphological properties and relationship to $\mathrm{C} 1$ adrenergic neurons. Neuroscience 69:601-618. CrossRef Medline

Marina N, Abdala AP, Trapp S, Li A, Nattie EE, Hewinson J, Smith JC, Paton JF, Gourine AV (2010) Essential role of Phox $2 b$-expressing ventrolateral brainstem neurons in the chemosensory control of inspiration and expiration. J Neurosci 30:12466-12473. CrossRef Medline

Marina N, Abdala AP, Korsak A, Simms AE, Allen AM, Paton JF, Gourine AV (2011) Control of sympathetic vasomotor tone by catecholaminergic C1 neurones of the rostral ventrolateral medulla oblongata. Cardiovasc Res 91:703-710. CrossRef Medline

McAllen RM, May CN, Shafton AD (1995) Functional anatomy of sympathetic premotor cell groups in the medulla. Clin Exp Hypertens 17:209221. CrossRef Medline

McMullan S, Pilowsky PM (2010) The effects of baroreceptor stimulation on central respiratory drive: a review. Respir Physiol Neurobiol 174:3742. CrossRef Medline

Moreira TS, Takakura AC, Colombari E, Guyenet PG (2006) Central chemoreceptors and sympathetic vasomotor outflow. J Physiol 577: 369-386. CrossRef Medline

Nattie E, Li A (2010) Central chemoreception in wakefulness and sleep: evidence for a distributed network and a role for orexin. J Appl Physiol 108:1417-1424. CrossRef Medline

Paton JF, Boscan P, Pickering AE, Nalivaiko E (2005) The yin and yang of cardiac autonomic control: vago-sympathetic interactions revisited. Brain Res Brain Res Rev 49:555-565. Medline

Pilowsky PM, Jiang C, Lipski J (1990) An intracellular study of respiratory neurons in the rostral ventrolateral medulla of the rat and their relationship to catecholamine-containing neurons. J Comp Neurol 301:604-617. CrossRef Medline

Potts JT, Rybak IA, Paton JF (2005) Respiratory rhythm entrainment by somatic afferent stimulation. J Neurosci 25:1965-1978. CrossRef Medline

Reiner PB, Vincent SR (1986) The distribution of tyrosine hydroxylase, dopamine-B-hydroxylase, and phenylethanolamine- $\mathrm{N}$-methyltransferase immunoreactive neurons in the feline medulla oblongata. J Comp Neurol 248: 518-531. CrossRef Medline

Ritter S, Llewellyn-Smith I, Dinh TT (1998) Subgroups of hindbrain cate- cholamine neurons are selectively activated by 2-deoxy-D-glucose induced metabolic challenge. Brain Res 805:41-54. CrossRef Medline

Ruggiero DA, Anwar M, Gootman PM (1992) Presumptive adrenergic neurons containing phenylethanolamine $\mathrm{N}$-methyltransferase immunoreactivity in the medulla oblongata of neonatal swine. Brain Res 583:105-119. CrossRef Medline

Sapru HN (1996) Carotid chemoreflex. Neural pathways and transmitters. Adv Exp Med Biol 410:357-364. CrossRef Medline

Schiltz JC, Sawchenko PE (2007) Specificity and generality of the involvement of catecholaminergic afferents in hypothalamic responses to immune insults. J Comp Neurol 502:455-467. CrossRef Medline

Schreihofer AM, Guyenet PG (1997) Identification of C1 presympathetic neurons in rat rostral ventrolateral medulla by juxtacellular labeling in vivo. J Comp Neurol 387:524-536. CrossRef Medline

Sparta DR, Stamatakis AM, Phillips JL, Hovels $ø$ N, van Zessen R, Stuber GD (2012) Construction of implantable optical fibers for long-term optogenetic manipulation of neural circuits. Nat Protoc 7:12-23. CrossRef Medline

Spyer KM, Gourine AV (2009) Chemosensory pathways in the brainstem controlling cardiorespiratory activity. Philos Trans R Soc Lond B Biol Sci 364:2603-2610. CrossRef Medline

Stornetta RL, Sevigny CP, Guyenet PG (2002) Vesicular glutamate transporter DNPI/VGLUT2 mRNA is present in C1 and several other groups of brainstem catecholaminergic neurons. J Comp Neurol 444:191-206. CrossRef Medline

Stornetta RL, Macon CJ, Nguyen TM, Coates MB, Guyenet PG (2012) Cholinergic neurons in the mouse rostral ventrolateral medulla target sensory afferent areas. Brain Struct Funct. Advance online publication. doi: 10.1007/s00429-012-0408-3. CrossRef Medline

Sun MK (1996) Pharmacology of reticulospinal vasomotor neurons in cardiovascular regulation. Pharm Rev 48:465-494. Medline

Sun MK, Reis DJ (1996) Medullary vasomotor activity and hypoxic sympathoexcitation in pentobarbital-anesthetized rats. Am J Physiol 270: R348-R355. Medline

Sun MK, Spyer KM (1991a) Nociceptive inputs into rostral ventrolateral medulla spinal vasomotor neurones in rats. J Physiol 436:685-700. Medline

Sun MK, Spyer KM (1991b) Responses of rostroventrolateral medulla spinal vasomotor neurones to chemoreceptor stimulation in rats. J Auton Nerv Syst 33:79-84. CrossRef Medline

Teppema LJ, Veening JG, Kranenburg A, Dahan A, Berkenbosch A, Olievier C (1997) Expression of $c$-fos in the rat brainstem after exposure to hypoxia and to normoxic and hyperoxic hypercapnia. J Comp Neurol 388:169-190. CrossRef Medline

Vimercati C, Qanud K, Ilsar I, Mitacchione G, Sarnari R, Mania D, Faulk R, Stanley WC, Sabbah HN, Recchia FA (2012) Acute vagal stimulation attenuates cardiac metabolic response to beta-adrenergic stress. J Physiol 590:6065-6074. CrossRef Medline

Zanella S, Roux JC, Viemari JC, Hilaire G (2006) Possible modulation of the mouse respiratory rhythm generator by $\mathrm{A} 1 / \mathrm{C} 1$ neurones. Respir Physiol Neurobiol 153:126-138. CrossRef Medline 